\title{
Effect of geometrical properties on strength of externally prestressed steel-concrete composite beams
}

Anwar B. Abu-Sena PhD

Associate Professor of Steel Structures, Faculty of Engineering (Shoubra), Benha University, Benha, Egypt

\section{Ibrahim G. Shaaban PhD}

Senior Lecturer, University of West London, London, UK

(corresponding author: ibrahim.shaaban@uwl.ac.uk)

(Orcid:0000-0003-4051-341X)

\author{
Mohamed S. Soliman PhD \\ Lecturer, San Jose State University, San Jose, CA, USA \\ Khaled Abd-Allah Mohamed Gharib MSC \\ Lecturer and PhD student, Faculty of Engineering (Shoubra), \\ Benha University, Benha, Egypt
}

\begin{abstract}
A parametric study was carried out to investigate the structural behaviour of composite steel-concrete T-beams under different prestressing conditions. The studied parameters include different cases of loading, tendon profiles, beam spans, initial prestressing levels and different dimensions of steel sections and concrete deck. The studied beams were modelled by the finite-element software Ansys. The effect of three geometrical parameters was investigated for three different tendon profiles. It was found that straight tendon profiles are more appropriate for beams under distributed loads, whereas a draped tendon profile is more convenient for beams under concentrated loads. In addition, the ratio of the tension flange area to the compression flange area is the most effective geometrical parameter on the ultimate resistance of the studied prestressed beams. For instance, increasing this ratio from 1 to 3 resulted in increasing the additional resistance of the beam due to prestressing from 15.4 to $46 \cdot 1 \%$. For composite beams, the presence of the concrete slab prevented the lateral-torsional buckling and accordingly minimised the effect of the span. Moreover, increasing the slab thickness-to-width ratio resulted in enhancing the average increase in beam strength from 13.5 to $19.9 \%$.
\end{abstract}

\section{Introduction}

Two types of structures have been widely adopted for the construction of bridges during the past few decades; namely, prestressed concrete beams and composite steel beams. External prestressing of composite beams is mainly employed in bridge engineering, mostly to strengthen or rehabilitate existing structures. The associated advantages are generally attracting researchers to study further and enhance understanding of the performance of this type of bridge construction. Combining the major benefits from both of the aforementioned structures has attracted the attention of the designers of bridge systems towards using prestressed composite steel bridge in recent years. Externally prestressed steel-concrete composite members have been used since the late 1950s in buildings and bridge construction. In addition, external posttensioning has been extensively applied in existing bridges to strengthen structures or to increase the ultimate capacity to accommodate heavier loads. Composite steel-concrete beams prestressed with external tendons offer several major advantages; for example, elastic behaviour under heavier loads, increased ultimate capacity, improved fatigue and fracture behaviour (Lorenc and Kubica, 2006). Lorenc and Kubica (2006) studied the behaviour of composite beams prestressed with external tendons experimentally. It was concluded that in order to properly determine the load-carrying capacity of a composite beam prestressed by external tendons, the correct value of the force in the tendons in the ultimate state must be assumed. Chen and $\mathrm{Gu}$ (2005) investigated the ultimate load-carrying capacity of composite beams prestressed with external tendons under positive moment. It was observed that adding prestressing by external tendons to the composite beams may significantly increase the yield load and the ultimate resistance of these beams. Dall'Asta et al. (2007) conducted research on a simplified method for failure analysis of concrete beams prestressed with external tendons. They concluded that the flexural strength of externally prestressed beams could not be evaluated by a local analysis of the critical sections.

Experimental and analytical studies were carried out to investigate the behaviour of simply supported prestressed steelconcrete composite beams by Nie et al. (2007). They proposed a reduced stiffness method for calculating the deflection of overstressed composite beams. Zona et al. (2009) studied a simplified method for the analysis of externally prestressed steel-concrete composite beams. They introduced a simplified method for evaluating the tendon traction increment at collapse and consequently the beam flexural strength without requiring a non-linear analysis of the whole beam-tendon structural system. The behaviour of prestressed concrete bridge girders was studied by Angomas (2009). He concluded that the Aashto LRFD 2004 (Aashto, 2006) refined method is reasonably accurate in predicting the prestressing losses. A finite-element model for composite beams prestressed by external slipping tendons was presented by Dall'Asta and Zona (2005). The proposed formulation involves composite beams with deformable shear connection. The authors stated that the 
proposed approach could be implemented in existing nonlinear finite-element programs with no additional iterative procedures. Choi et al. (2008) studied external post-tensioning of composite bridges by a rating equation considering the increment of a tendon force due to live loads. They illustrated a systematic procedure of external post-tensioning technique for strengthening or rehabilitation of steel-concrete composite bridges. Dabaon et al. (2005) investigated the ultimate behaviour of externally prestressed composite beams with partial shear connection. The authors presented three-dimensional and uniaxial finite-element models to describe the long-term behaviour of such beams. Based on the reported results, the authors concluded that the long-term factors have a significant effect on the behaviour of beams. They concluded also that relaxation of the tendon had the most major effect among other factors.

El-Zohairy and Salim (2017) implemented a parametric study for post-tensioned composite beams with external tendons. The results demonstrated that, at the same tendon eccentricity, the trapezoidal profile shows better behaviour for the strengthened beams. However, more ductility is obtained when using the straight tendon profile. Chandramohanmouli and Kumar (2017) carried out a non-linear finite-element analysis to investigate the behaviour up to failure of simply supported composite steel-concrete beams with external prestressing. The analytical tests carried out for the different cases studied indicated that the load-deflection behaviour and the ultimate loads were in good agreement with the published experimental results. Ibrahim et al. (2012) investigated the effect of several important parameters on the behaviour of external prestressed composite steel-concrete beams by conducting a parametric study. The finite-element results for simply supported beams with full shear interactions showed stiffer behaviour compared to beams with partial shear interactions. Liban and Tayşi (2017) examined the behaviour up to failure of cantilever composite steel-concrete beams which were prestressed externally. The authors concluded that adding prestressed tendons to composite beams significantly increased the yield load and the ultimate load. They concluded also that the farther the tendons are located from the neutral axis, the greater is the increase in strength. Ibrahim and Salman (2015) investigated analytical continuous composite steel-concrete beam with external prestressing by conducting a parametric study. It was found that, as the compressive strength of the concrete and the effective prestressing stress increased, the ultimate load capacity increased.

Lou and Xiang (2010) described a numerical analysis procedure of second-order effects of externally prestressed concrete beams. The authors revealed that the second-order effects are the most important characteristics which distinguish an external tendon system from an internal unbonded one. This study led to a conclusion that the provision of one deviator at the section of the maximum beam deflection can effectively minimise the second-order effects for simply supported prestressed concrete beams with external straight horizontal tendons, even for a very slender beam. Ibrahim et al. (2015) implemented a parametric study of composite steel-concrete beams with external prestressing to investigate the factors affecting their behaviour. It was found from the numerical analysis that the predicted ultimate loads are increased by increasing compressive strength of concrete, effective prestressing stress, the ratio of the depth to the width of concrete slab, shear interactions, or ratio of top flange area to bottom flange area. It was also found that stiffener web plate had no significant effect on the behaviour of prestressed composite steelconcrete beams. Bukka et al. (2016) conducted a study on the non-linear analysis of the composite beam slab junction with shear connectors using Ansys 14 (Ansys, 2013). They stated that composite action depends on the interaction between the reinforced concrete slab, the steel profile and the shear connection. Therefore, a perfect composite action cannot be obtained in practice due to the deformability of the shear connectors. The behaviour of steel box girders prestressed with external tendons was studied by Kambal and Jia (2017). A finite-element model for the flexural behaviour of a simply supported steel girder with a box-shaped cross-section and prestressed by external tendons was established. Box girders with and without prestressing were tested to evaluate the effectiveness of the technique. It was concluded that prestressing improves the flexural capacity of a girder and its effect is proportional to the size of the applied external load.

Shiming and Yuanlin (2010) investigated the inelastic buckling of steel-concrete composite beams prestressed with external tendons. A parametrical analysis was carried out to predict the load-carrying performance and buckling moment resistance of prestressed composite beams. The computed buckling moment ratios were compared with the Chinese codified steel column design curve. The authors concluded that a tentative design method based on this curve could be used in the assessment of buckling strength of composite beams in a term of the modified slenderness proposed by the authors. Numerical modelling of externally prestressed steel-concrete composite beams was carried out by Tiejiong et al. (2016). Geometric and material non-linearities were considered, as well as time-dependent effects. The authors validated the proposed model by comparisons with available experimental data. Typical short- and long-term responses of steel-concrete composite beams with and without external prestressing were evaluated.

\section{Aim of the study}

The aim of the current theoretical investigation is to study the ultimate strength of externally prestressed composite steelconcrete T-beams under different geometrical parameters. This study includes different cases of loading, tendon profiles, beam spans, initial prestressing levels and different dimensions of steel sections and concrete deck thickness. The finite-element analysis was carried out using the computer program Ansys 
14.0 (Ansys, 2013). The results were first verified by the experimental results available in the literature and then an extensive study for the different geometrical parameters involved modelling 2160 studied beams was carried out to assess the effect of the geometrical parameters on the behaviour of composite T-beams.

\section{Finite-element modelling of the studied beams}

The Ansys program version 14.0 (Ansys, 2013) was used for analysing the externally prestressed composite beams. A threedimensional brick element with eight nodes from the Ansys element library was used to model the concrete slab (Solid65). The most important aspect of this element is the treatment of non-linear material properties. A three-dimensional fournode shell element (Shell181) was used to represent the steel beam flanges and webs. Shell181 is well suited to model linear, warped and moderately thick shell structures. The Link180 element is a uniaxial tension-compression element with three degrees of freedom at each node. It was used to represent the external cable and reinforcement bars. The initial prestressing on a tendon was applied as the initial strain in link elements, which represents the prestressing of the tendons. Reduction in prestressing stress was noted as the initial strain was applied, immediately at first load step, and made the beam cambered. Thus, the initial strain was increased to overcome that reduction in stress to assure that the targeted initial prestressing level is achieved. The frame element (Beam188), which is a uniaxial element with tension, compression, torsion and bending capabilities, was used to model shear connectors. Each shear connector is presented by four frame elements, one element between the top of the upper steel flange and the bottom of the concrete slab and three elements in the concrete slab. The bond between the steel section and concrete deck of the composite section is very weak compared with the junction associated with shear connectors; therefore, it was neglected in modelling the composite action. In order to overcome large displacement effects, all of the aforementioned elements have large deflection and large strain capabilities.

Beams in the present study are simply supported and the supports were modelled as hinges, with roller supports existing at the ends. The hinge support was modelled by constraining nodes in the vertical and longitudinal direction $\left(\left(U_{y}, U_{z}\right)=0\right)$, as shown in Figure 1(a). To model the roller support, nodes of the end line at the bottom flange were constrained in the vertical direction $\left(U_{y}=0\right)$, as shown in Figure 1(b). All nodes at hinged and roller supports were also constrained in the horizontal direction $\left(U_{x}=0\right)$ for stability purposes. Uniformly distributed loads were applied on the middle line of nodes on the top surface of the concrete slab. Concentration of stress in the concrete slab at the point of concentrated loads is prevented by using a small bearing plate placed between the concentrated loads and the concrete slab. Failure in the finiteelement modelling is usually accompanied by increasing iterative displacements and a continuous growth in the dissipated energy. Hence, the convergence of the iterative process cannot be achieved, and a message is given by the software to indicate that beam failure is achieved.

\section{Modelling of material properties}

In order to obtain an accurate modelling of the studied composite steel-concrete beams, choosing the appropriate material modelling for the concrete and steel is essential. This could be achieved by utilising the plasticity model for the stress-strain relation of concrete under compressive stresses based on work done by Desayi and Krishnan (1964); as shown in Figure 2(a). A multi-linear curve was used to help with convergence of the non-linear solution algorithm. Concrete subjected to tensile stresses was allowed to crack because minor tensile stresses were expected for the concrete slab on top of the simply supported composite beam. The stress-strain diagram of steel

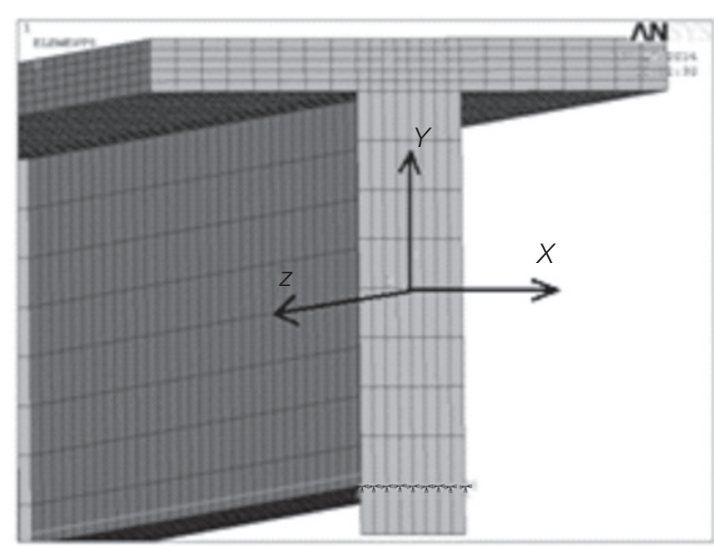

(a)

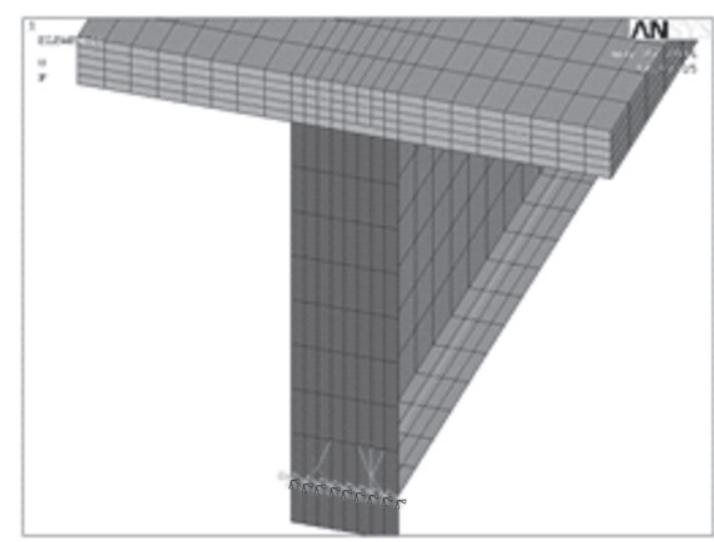

(b)

Figure 1. Boundary conditions of beam: (a) hinged support condition; (b) roller support condition 


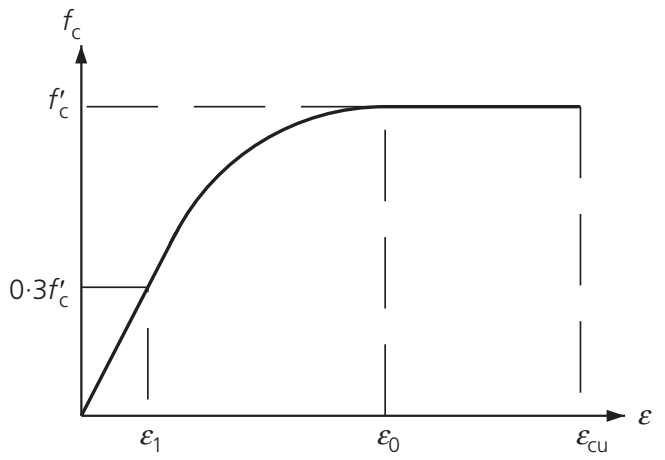

(a)

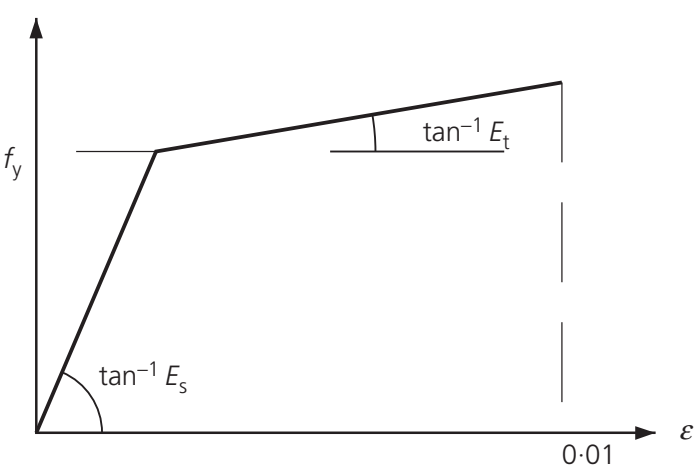

(b)

Figure 2. Stress-strain relationships used in modelling the studied beams: (a) simplified compressive uniaxial stress-strain curve for concrete (Desayi and Krishnan, 1964); (b) alternative bilinear stress-strain relationship for steel (CEN, 1993)

Table 1. Material properties of samples for verification purposes

\begin{tabular}{lrrrrrl} 
Sample beam & $\boldsymbol{f}_{\mathrm{pe}}: \mathbf{M P a}$ & $\boldsymbol{f}_{\mathrm{py}}: \mathbf{M P a}$ & $\boldsymbol{f}_{\mathbf{c}}^{\prime}: \mathbf{M P a}$ & $\boldsymbol{f}_{\mathbf{y}}$ (flange): MPa & $\boldsymbol{f}_{\mathbf{y}}$ (web): MPa & Reference \\
\hline VB1 & 544 & 910 & 33.4 & 367 & 367 & Saadatmanesh et al. (1989) \\
VB2 & 1046 & 1620 & 40.0 & 411.6 & 411.6 & Ayyub et al. (1990)
\end{tabular}

$f_{\mathrm{pe}}$, effective prestress on tendon at initial state; $f_{\mathrm{py}}$, yield strength of tendon; $f_{\mathrm{c}}^{\prime}$, ultimate compressive strength of concrete slab; $f_{\mathrm{y}}$, yield strength of steel beam

under either tensile stresses or compressive stresses, for simplicity, was assumed to be two straight lines: the first line starts from the origin with a slope equal to $E_{\mathrm{s}}$ up to $f_{\mathrm{y}}$, and the second line was horizontal. However, for practical software applications the second line is assumed to have a very small slope. Therefore, the bilinear stress-strain relationship indicated in Figure 2(b) was adopted. The strain-hardening modulus $\left(E_{\mathrm{t}}\right)$ is assumed to be $0.03 E_{\mathrm{s}}$ to avoid convergence problems during iteration (CEN, 1993).

\section{Verification of finite-element analysis}

The aim of this section is to verify the Ansys results of the non-linear finite-element model developed to investigate the behaviour and strength of prestressed composite steel-concrete beams. The verification study is established to prove that both the adopted idealisation and elements are adequate to accurately predict the failure loads, deformed shape and load-displacement relations compared to the experimental results provided by other researchers in the literature. For this purpose, results obtained from Ansys finite-element analysis are compared to the corresponding values obtained by previous experimental research studies. There are many reports that present experimental work on externally prestressed composite beams (Chen, 2005; Chen et al., 2009; Kim and Lee, 2011; Lorenc and Kubica, 2006; Nie et al., 2007; Safan and Kohoutkova, 2001; Zong et al., 2002). In this section only two reports are considered for verification. Hence, two

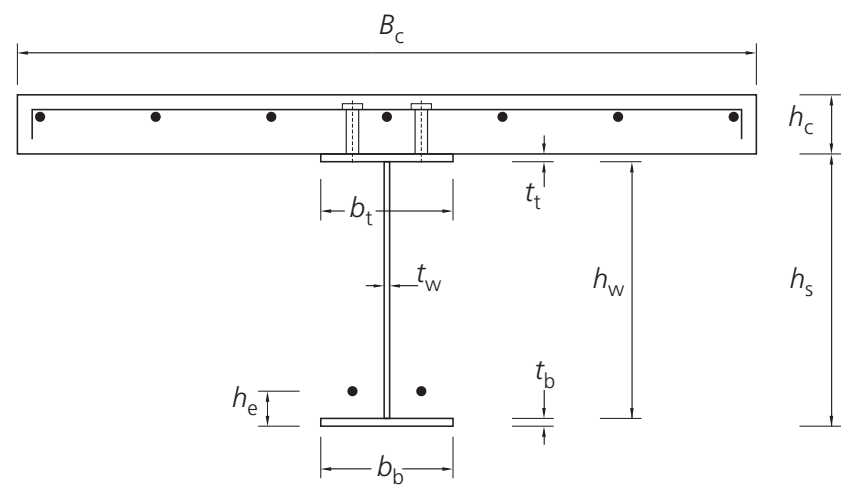

Figure 3. Typical cross-section of externally prestressed composite beam

different types of prestressed composite steel-concrete beams with available experimental results have been analysed. The material properties of the two verification sample beams are summarised in Table 1 for the components of the composite beams including steel beam, concrete slab and prestressing tendon. A typical cross-section of an externally prestressed composite beam is shown in Figure 3. The geometrical properties of the verification sample beams are presented in Table 2. 
Table 2. Geometrical properties of sample beams for verification purposes (notation as defined in Figure 3)

\begin{tabular}{lcccccccc} 
Sample beam & $\boldsymbol{h}_{\mathbf{s}}: \mathbf{m m}$ & $\boldsymbol{h}_{\mathbf{w}}: \mathbf{m m}$ & $\boldsymbol{t}_{\mathbf{w}}: \mathbf{m m}$ & $\boldsymbol{b}_{\mathbf{t}}$ and $\boldsymbol{b}_{\mathbf{b}}: \mathbf{m m}$ & $\boldsymbol{t}_{\mathbf{t}}$ and $\boldsymbol{t}_{\mathbf{b}}: \mathbf{m m}$ & $\boldsymbol{B}_{\mathbf{c}}: \mathbf{m m}$ & $\boldsymbol{h}_{\mathbf{c}}: \mathbf{m m}$ & $\boldsymbol{h}_{\mathbf{e}}: \mathbf{m m}$ \\
\hline VB1 & 352 & 333 & $6 \cdot 8$ & 172 & $9 \cdot 5$ & 915 & 76 & -57 \\
VB2 & 371 & 352 & $6 \cdot 8$ & 172 & $9 \cdot 5$ & 1070 & 90 & 30
\end{tabular}

Note: $h_{\mathrm{e}}$ has positive sign for tendon above flange and negative sign for tendon below flange

\subsection{The first verification beam (VB1)}

Saadatmanesh et al. (1989) tested a simply supported composite steel-concrete beam prestressed with high-strength steel tendon and subjected to two concentrated loads, as shown in Figure 4(a). The steel beam is prestressed with two $16 \mathrm{~mm}$ dia. tendons running the full beam length, $57 \mathrm{~mm}$ below the bottom (tension) flange. The experimental and finite-element model load-deflection curves are shown in Figure 4(b). Good agreement was obtained between the experimental loaddeflection curve and the predicted finite-element curve throughout the entire loading range of the tested beam. It can be seen from Figure 4(b) that the computed ultimate load is very close to the experimental ultimate load. The predicted ultimate load level $(64 \cdot 14 \mathrm{t})$ was detected quite well compared with that experimentally observed $(64 \cdot 1 \mathrm{t})$. The deformed shape for the camber arising from the effect of the prestressing force in the external tendon is shown in Figure 4(c), and the deformed shape due to externally applied loads at the ultimate state is shown in Figure 4(d).

\subsection{The second verification beam (VB2)}

Ayyub et al. (1990) tested three prestressed composite steelconcrete beams (A, B and C) under positive bending moment. Beam $C$ was selected as VB2 for the current analysis. As shown in Figure 5(a), the beam VB2 is prestressed with a draped tendon profile. The tendons are anchored at both ends of the composite section, $32 \mathrm{~mm}$ below the top flange, and were positioned between the loading points $30 \mathrm{~mm}$ above the bottom flange. The load-mid-span deflection curve of the prestressed composite steel-concrete beam (VB2) obtained from the finite-element analysis was in good agreement with the corresponding experimental data, as shown in Figure 5(b). The ratio of the experimental ultimate load to the predicted one was 0.94 . The camber due to effective prestressing in the first load step is shown in Figure 5(c). The deflected shape due to external force applied at ultimate load is shown in Figure 5(d).

\section{Parametric study}

After validating the analysis tool, a finite-element study was conducted to determine the parameters that may affect the behaviour and strength of prestressed composite beams. It is worth mentioning that limitations and recommendations specified by codes of practice were satisfied in the selected specimens. Table 3 presents the dimensions of the steel sections. It can be observed from Table 3 that the web depth-to-thickness ratio and the flange width-to-thickness ratio are selected to avoid local buckling according to design codes recommendations (CEN, 1993). In this study, beams of steel sections groups $\mathrm{A}$ and $\mathrm{B}$ are assigned to $8.00,10.00$ and $12.00 \mathrm{~m}$ spans, whereas deeper beams with steel sections groups $\mathrm{C}$ and $\mathrm{D}$ are assigned to $12 \cdot 00,14.00$ and $16.00 \mathrm{~m}$ spans. The concrete deck connected to steel sections has a concrete deck thickness-to-width ratio, $h_{\mathrm{c}} / B_{\mathrm{c}}$, of $0 \cdot 10,0 \cdot 12$ and $0 \cdot 145$. The total concrete deck cross-sectional area was considered to be $1000 \mathrm{~cm}^{2}$ for the three $h_{\mathrm{c}} / B_{\mathrm{c}}$ values in order to keep the concrete area constant. The width and thickness of the concrete deck are selected in accordance with the limits of the design codes (CEN, 1993). The varieties of steel sections and concrete deck dimensions with different spans provide 108 non-prestressed composite beams (NP). To produce prestressed composite beams, the studied beams were prestressed by two tendons, each of which had strands with $150 \mathrm{~mm}^{2}$ crosssectional area. Tendons were anchored to $35 \mathrm{~mm}$ plates at the ends and adjusted to their positions by $15 \mathrm{~mm}$ saddle plates. The tendons were not connected to the saddle plates directly, but through springs which allowed for slippage between them. The initial prestressing applied on tendons induced three different stress levels of $0 \cdot 4 F_{\mathrm{y}}, 0 \cdot 5 F_{\mathrm{y}}$ and $0 \cdot 6 F_{\mathrm{y}}$, to satisfy the design codes' limitations.

Tendons are adjusted in three different profiles, as shown in Figure 6. The first tendon profile (SA) consists of two straight tendons located $3 \mathrm{~cm}$ above the bottom flange, adjusted by four saddle plates, as shown in Figure 6(a). The second tendon profile (SB) also consists of two straight tendons located $3 \mathrm{~cm}$ below the bottom flange, adjusted by four saddle plates, as shown in Figure 6(b). The third tendon profile (DR) has a draped shape and consists of two tendons, as shown in Figure 6(c). A typical cross-section of these beams is shown in Figure 3. The non-prestressed composite beams and the prestressed composite beams for the three tendon profiles were analysed twice: once under two concentrated loads $1.60 \mathrm{~m}$ apart and also under uniformly distributed loads, to produce results for a total number of 2160 beams. Table 4 summarises the properties of the materials of the prestressed composite beams. Full composite action between the steel sections and the concrete slab was achieved by providing sufficient shear connectors.

\section{Results and discussion}

The effect of the previously mentioned parameters was investigated for each tendon profile for beams subjected to 

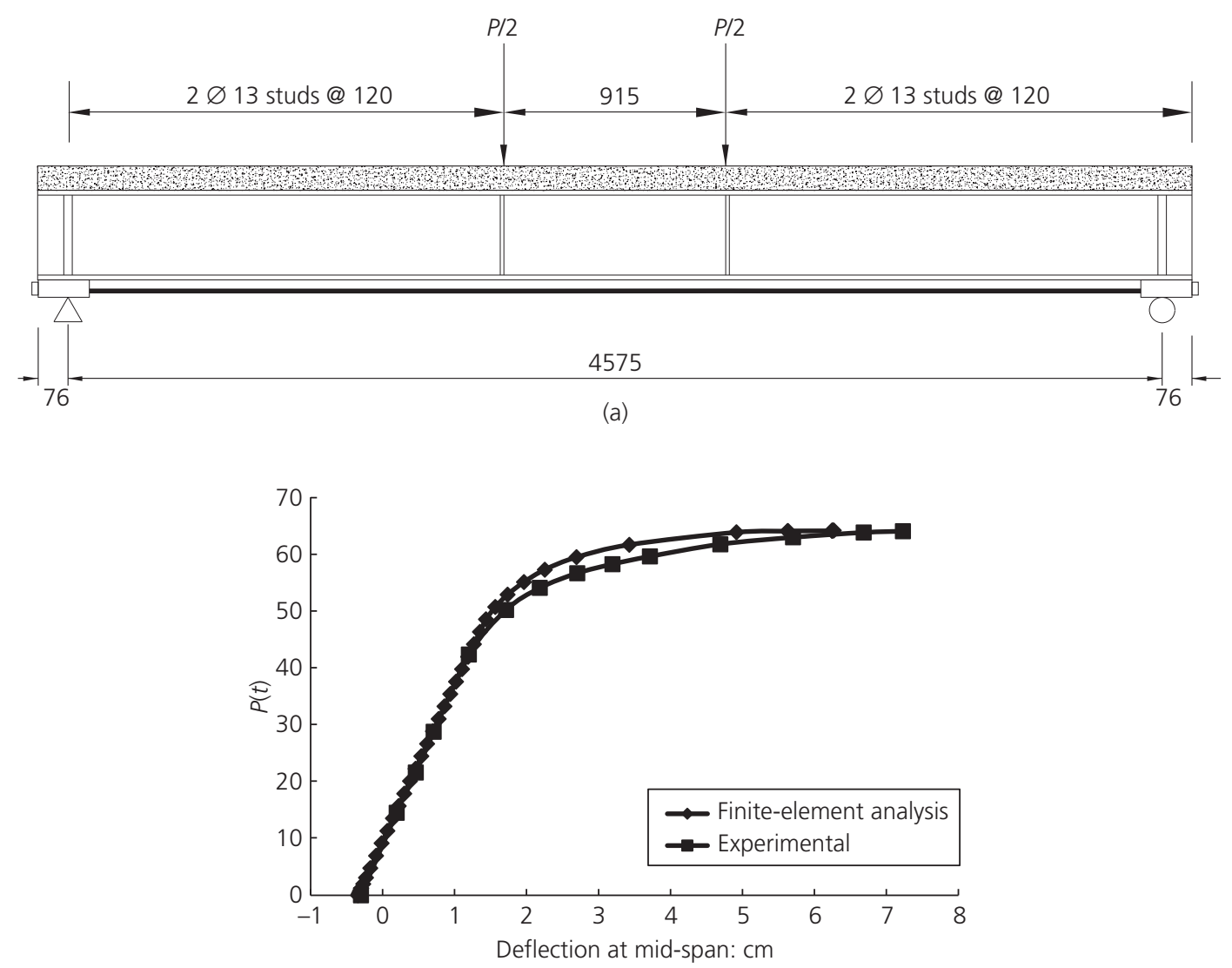

(b)

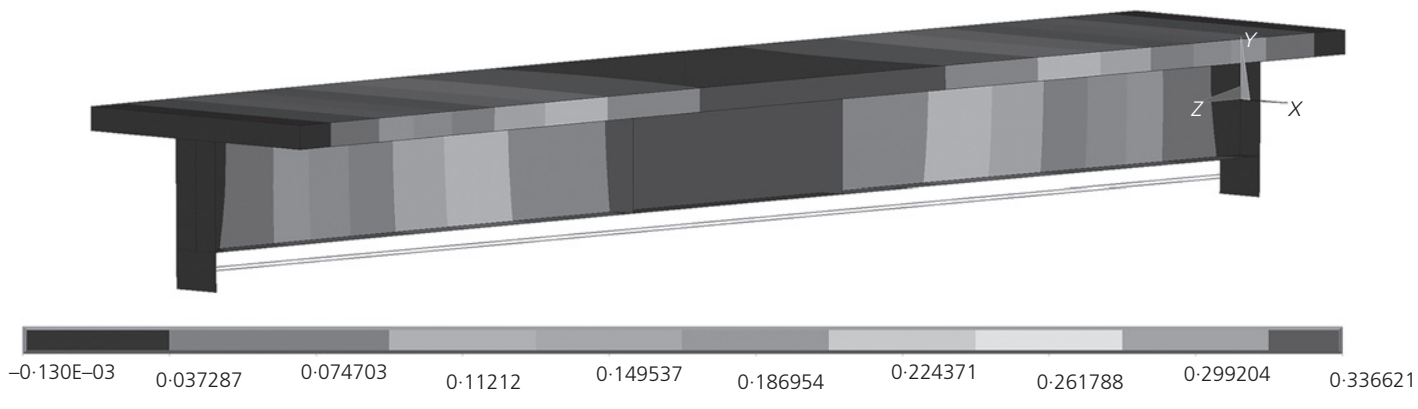

(c)

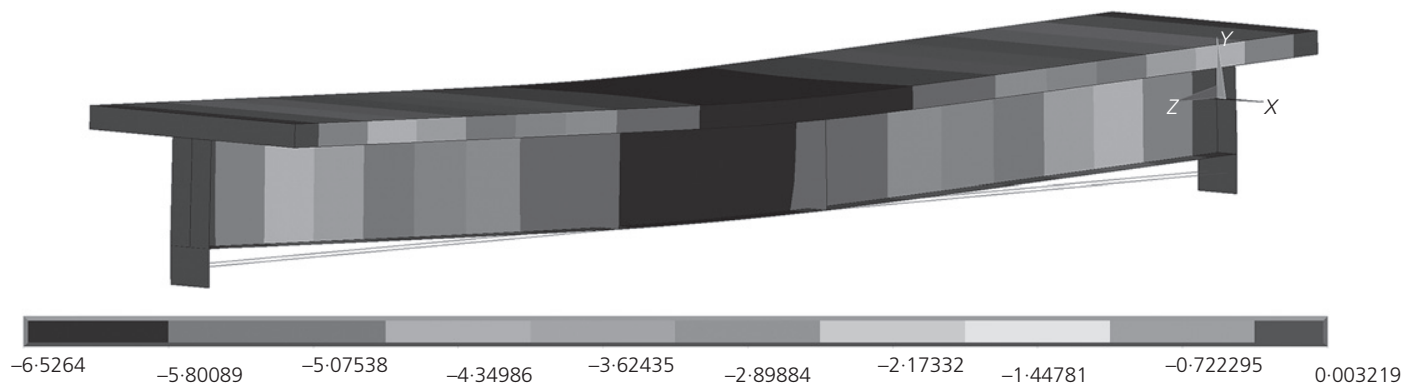

(d)

Figure 4. Details, deformed shapes and load-deflection results for beam VB1 (Saadatmanesh et al., 1989): (a) details of the first sample studied beam (all dimensions are in $\mathrm{mm}$ ); (b) load-deflection curve; (c) initial camber (cm); (d) at ultimate state $(\mathrm{cm})$ 


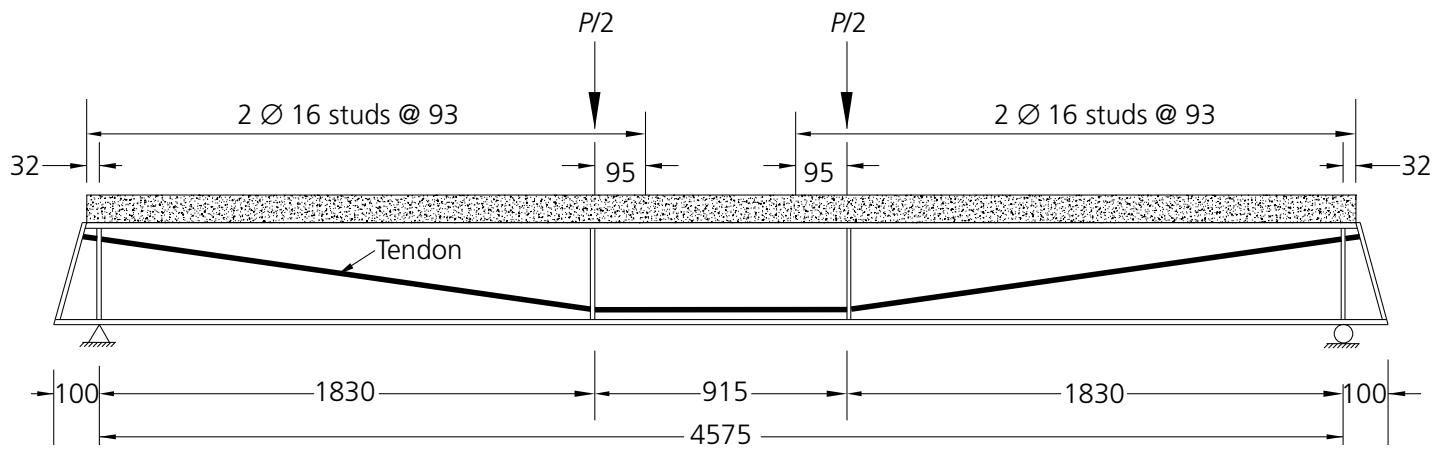

(a)

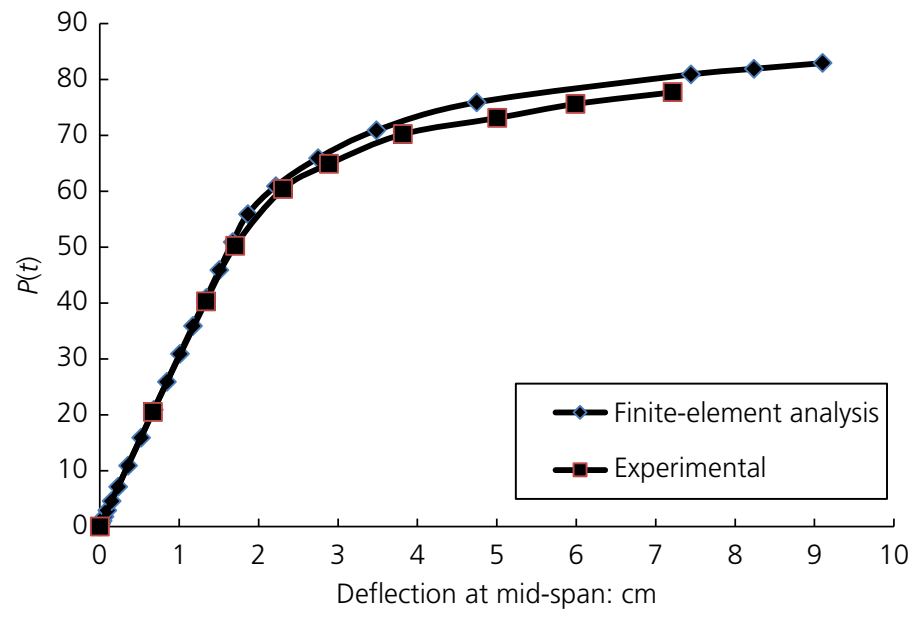

(b)
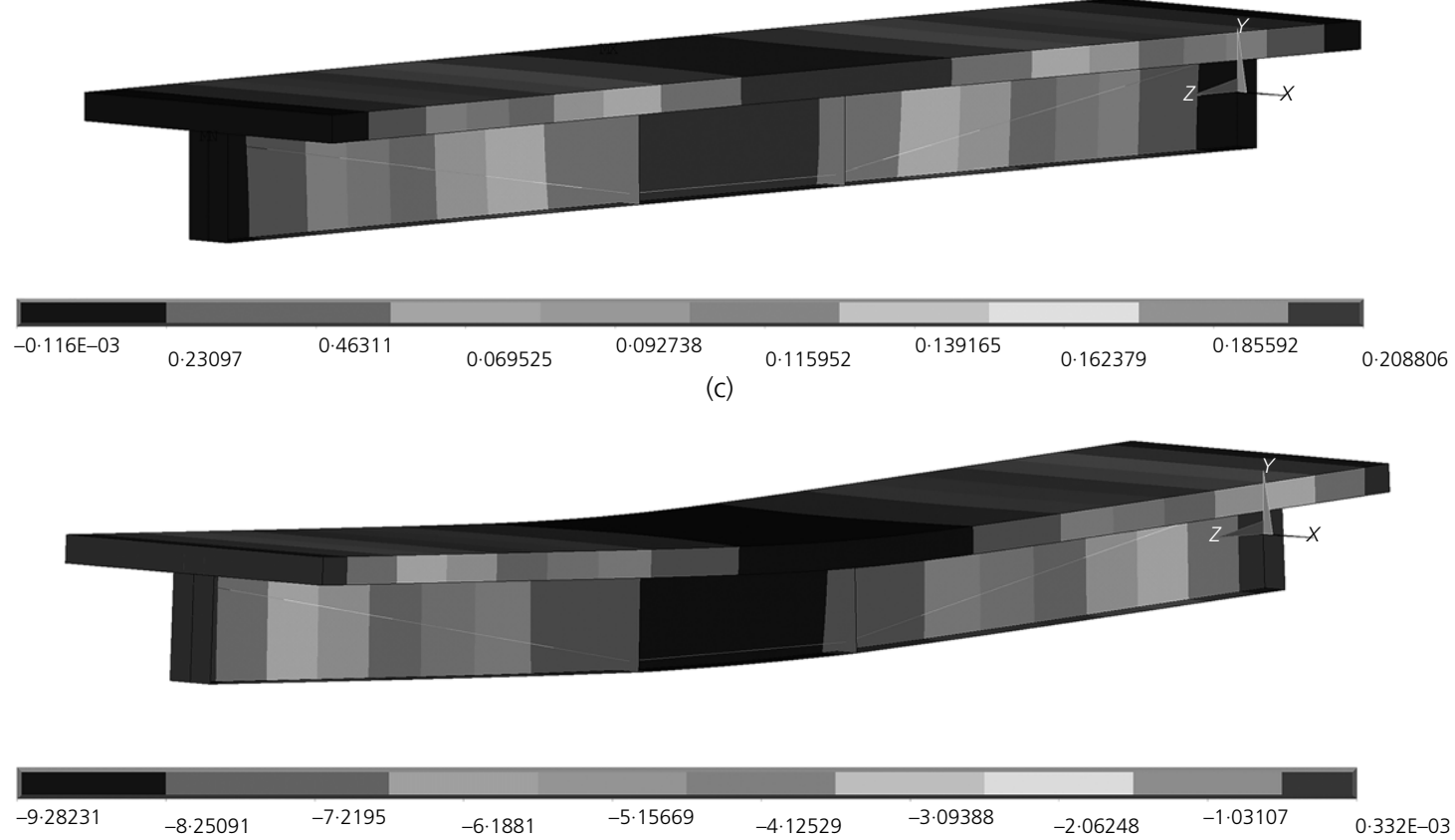

(d)

Figure 5. Details, deformed shapes and load-deflection results for beam VB2 (Ayyub et al., 1990): (a) details of the second sample studied beam (all dimensions are in $\mathrm{mm}$ ); (b) load-deflection curve; (c) initial camber (cm); (d) at ultimate load (cm) 
Table 3. Steel cross-sectional dimensions

\begin{tabular}{lcrccccc} 
Section & $\begin{array}{c}\boldsymbol{h}_{\mathbf{w}}: \\
\mathbf{m m}\end{array}$ & $\begin{array}{c}\boldsymbol{t}_{\mathbf{w}}: \\
\mathbf{m m}\end{array}$ & $\begin{array}{c}\boldsymbol{b}_{\mathbf{b}}: \\
\mathbf{m m}\end{array}$ & $\begin{array}{c}\boldsymbol{t}_{\mathbf{b}}: \\
\mathbf{m m}\end{array}$ & $\begin{array}{c}\boldsymbol{b}_{\mathbf{t}}: \\
\mathbf{m m}\end{array}$ & $\begin{array}{c}\boldsymbol{t}_{\mathbf{t}}: \\
\mathbf{m m}\end{array}$ & $\boldsymbol{A}_{\mathbf{f b}} / \boldsymbol{A}_{\mathbf{f t}}$ \\
\hline A1 & 500 & 8 & 200 & 10 & 200 & 10 & 1 \\
B1 & 500 & 8 & 300 & 16 & 300 & 16 & \\
C1 & 750 & 10 & 200 & 10 & 200 & 10 & \\
D1 & 750 & 10 & 300 & 16 & 300 & 16 & \\
A2 & 500 & 8 & 222 & 12 & 167 & 8 & 2 \\
B2 & 500 & 8 & 320 & 20 & 229 & 14 & \\
C2 & 750 & 10 & 222 & 12 & 167 & 8 & \\
D2 & 750 & 10 & 320 & 20 & 229 & 14 & \\
A3 & 500 & 8 & 250 & 12 & 143 & 7 & 3 \\
B3 & 500 & 8 & 360 & 20 & 200 & 12 & \\
C3 & 750 & 10 & 250 & 12 & 143 & 7 & \\
D3 & 750 & 10 & 360 & 20 & 200 & 12 &
\end{tabular}

concentrated loads or distributed loads. For each parameter, the results of parametric study are presented generally and the results for the two main sections are discussed in detail.

\subsection{Effect of steel flanges area ratio}

It may be an advantage to use steel section having a relatively larger bottom flange compared to the top flange. Therefore, the steel section flanges area ratio is an important parameter. The steel flanges area ratio is the result of dividing the area of the bottom flange, $A_{\mathrm{fb}}$ (flange in tension), by the area of top flange, $A_{\mathrm{ft}}$ (flange in compression). The variation of the prestressed composite beams' flexural capacities with the steel flanges area ratio will be presented for different tendon profiles hereafter in the next subsections and as shown in Figures 7-12.
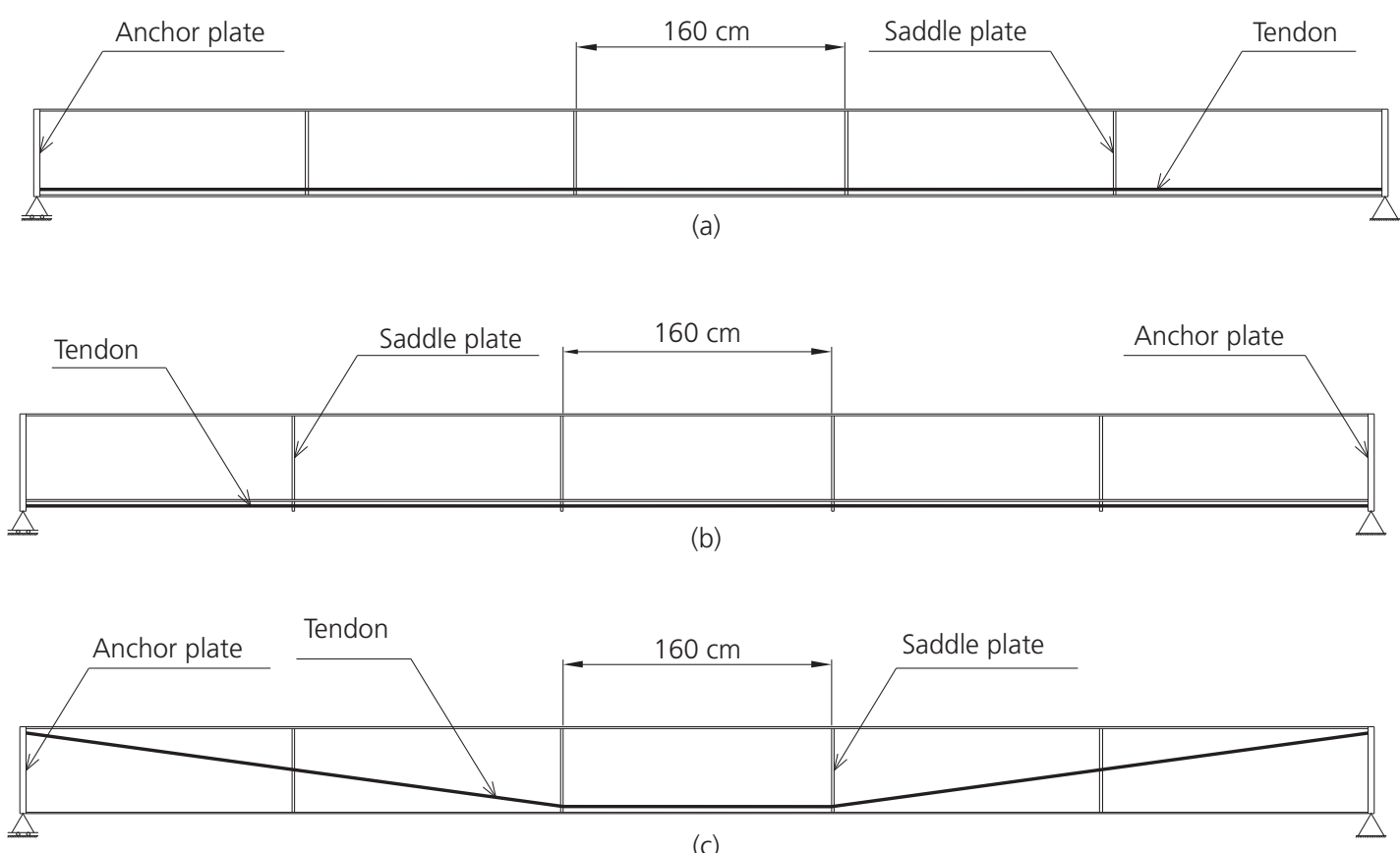

Figure 6. Tendon profiles: (a) first tendon profile (SA); (b) second tendon profile (SB); (c) third tendon profile (DR)

Table 4. Material properties of prestressed composite beams

$\begin{array}{lllr}\text { Material } & \text { Parameter } & \text { Symbol } & \text { Value } \\ \text { Concrete } & \text { Compressive strength: MPa } & F_{\mathrm{c}}^{\prime} & 30 \\ & \text { Modulus of elasticity: MPa } & E_{\mathrm{c}} & 25743 \\ \text { Steel beam, steel plates and } & \text { Yield stress: MPa } & F_{\mathrm{y}} & 360 \\ \quad \text { reinforcement, and studs } & \text { Ultimate strength: MPa } & F_{\mathrm{u}} & 520 \\ & \text { Modulus of elasticity: MPa } & E_{\mathrm{s}} & 210000 \\ \text { Prestressing tendon } & \text { Yield stress: MPa } & F_{\mathrm{py}} & 1680 \\ & \text { Ultimate strength: MPa } & F_{\mathrm{pu}} & 1860 \\ & \text { Modulus of elasticity: MPa } & E_{\mathrm{ps}} & 200000\end{array}$




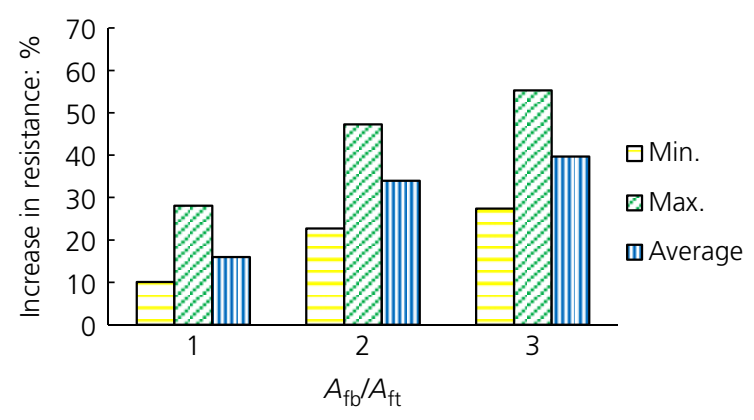

(a)

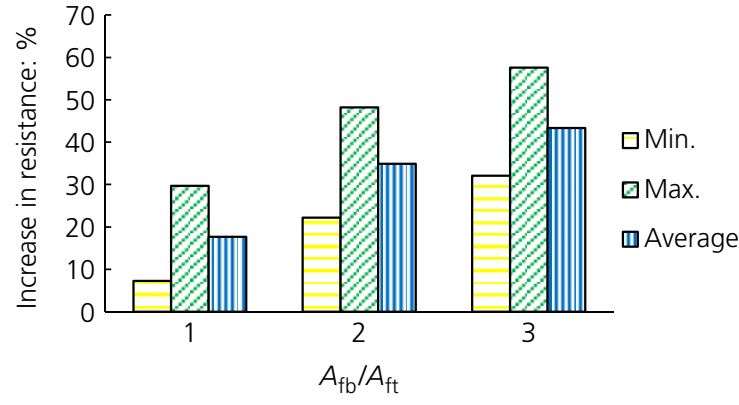

(b)

Figure 7. Effect of steel flange area ratio on the ultimate resistance of beams (SA): (a) under concentrated loads; (b) under distributed loads

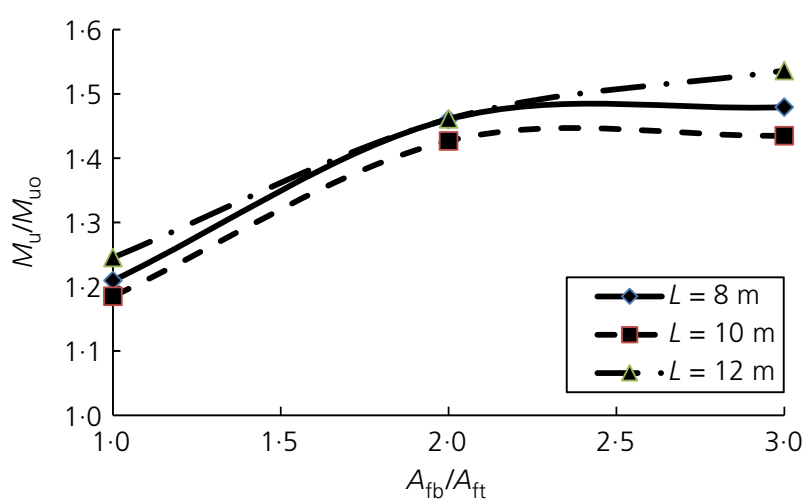

(a)

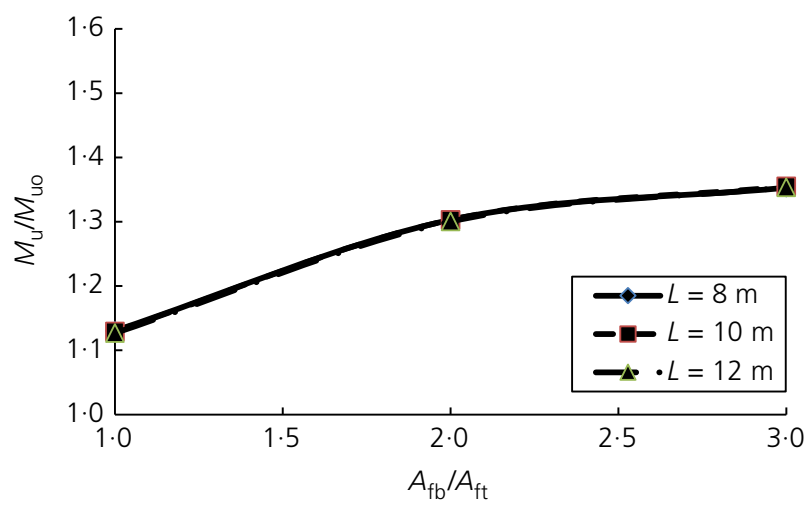

(c)

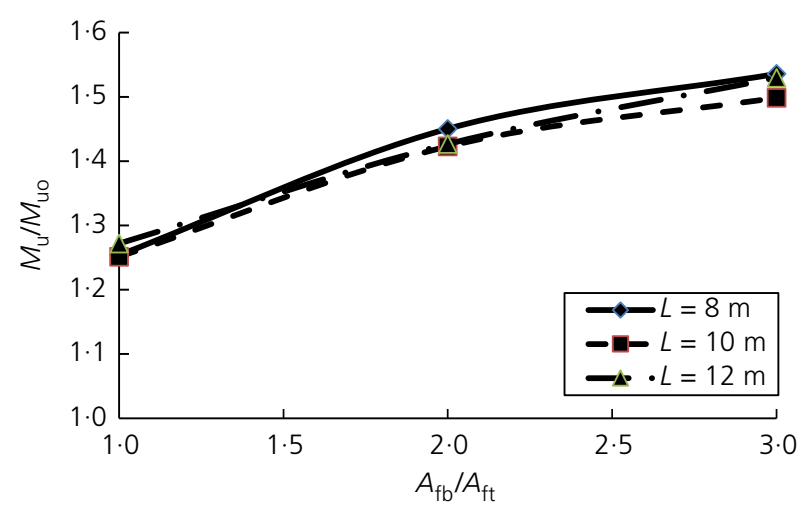

(b)

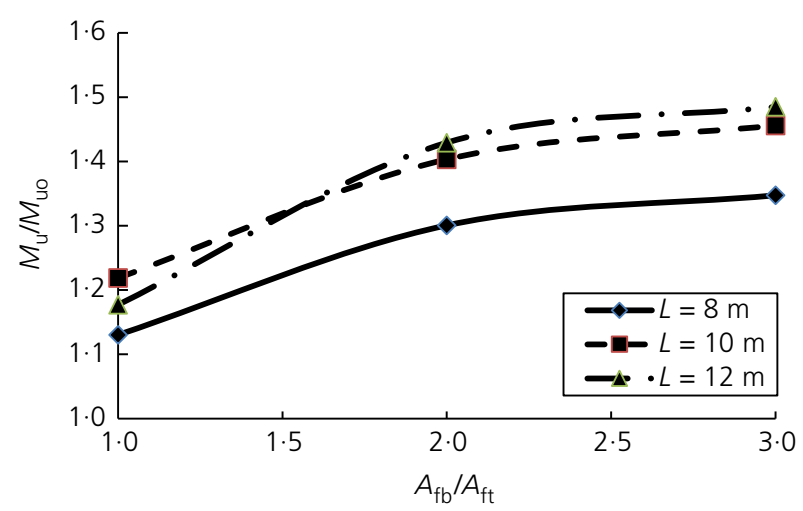

(d)

Figure 8. Effect of steel flange area ratio on the ultimate resistance of externally prestressed steel-concrete composite beams (PCB) (SA): (a) group A under concentrated loads; (b) group A under distributed loads; (c) group B under concentrated loads; (d) group B under distributed loads

7.1.1 Straight tendon profile above tension flange (SA) Ultimate resistance values, $M_{\mathrm{u}}$, of composite beams prestressed with the first tendon profile (SA) were compared with ultimate resistance values, $M_{\mathrm{u} 0}$, of the corresponding nonprestressed composite beam with $\left(A_{\mathrm{fb}} / A_{\mathrm{ft}}=1 \cdot 0\right)$. The percentage of increase in ultimate resistance due to prestressing was calculated. The maximum, minimum and average percentage increases in ultimate resistance are shown in Figures 7(a) and 7(b) for beams under concentrated and distributed loads. It can be observed that the ultimate resistance of beams prestressed by a straight tendon above the bottom flange increased by increasing the steel flange area ratio. It can also be noticed that the effect of prestressing of composite beams under distributed loads is more significant than prestressing beams under concentrated loads. This effect may be attributed to the tendon profile, which has a straight profile above the bottom 


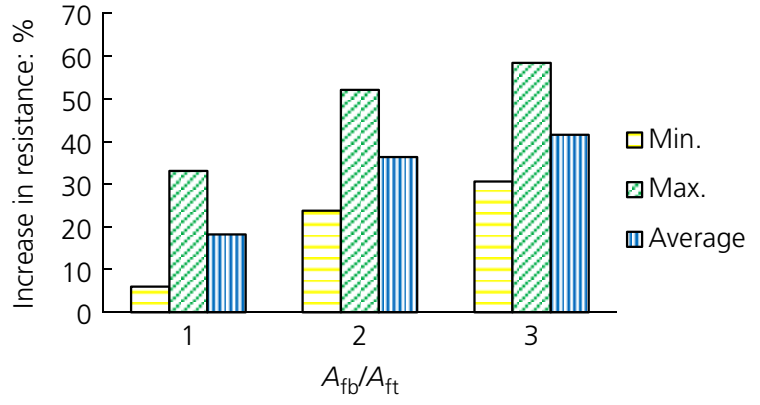

(a)

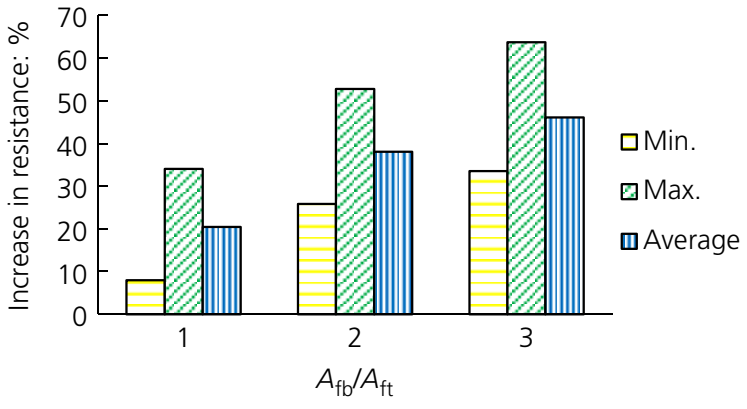

(b)

Figure 9. Effect of steel flange area ratio on the ultimate resistance of beams (SB): (a) under concentrated loads; (b) under distributed loads

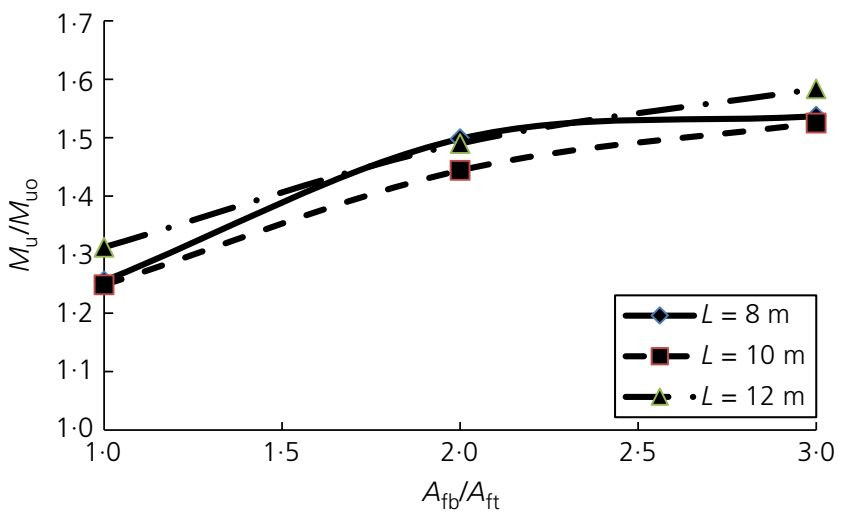

(a)

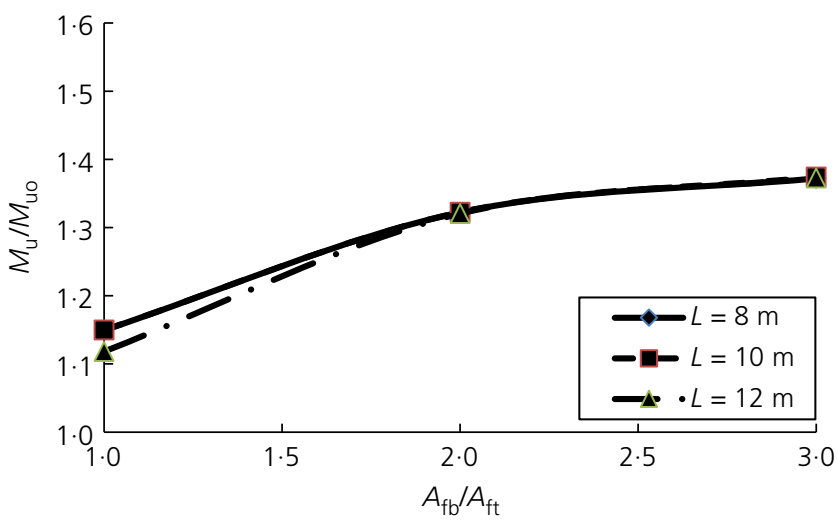

(c)

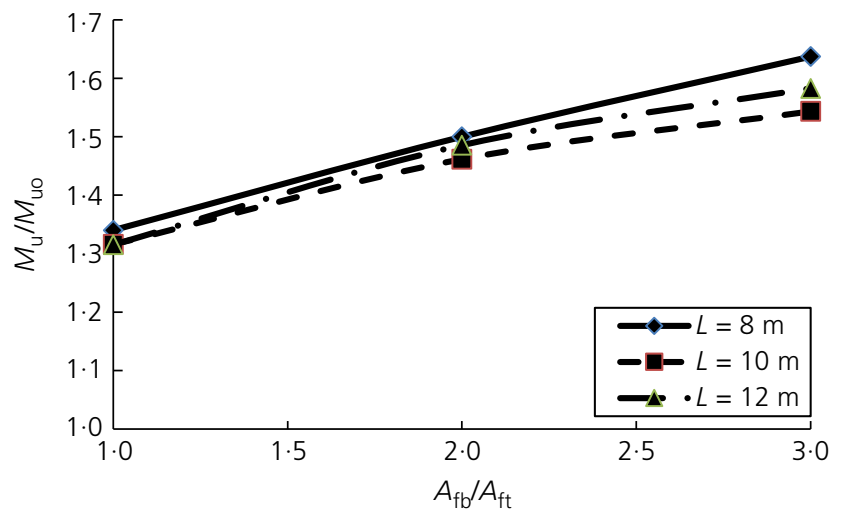

(b)

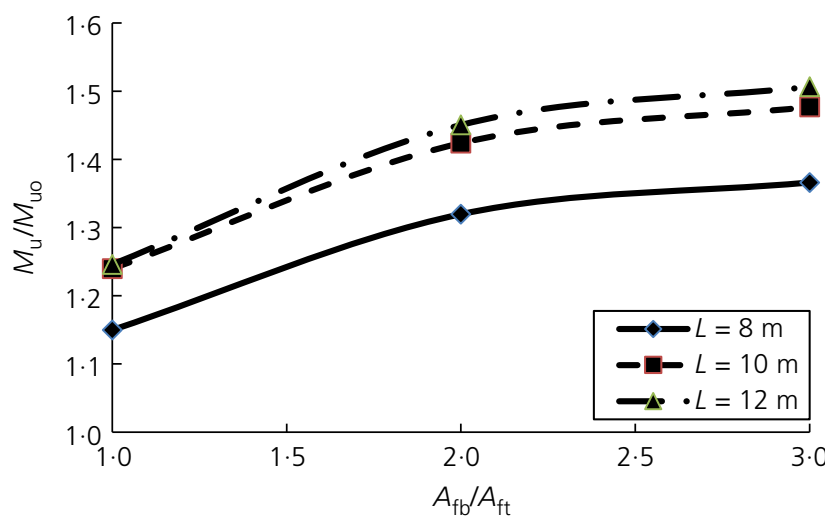

(d)

Figure 10. Effect of flange area ratio on the ultimate resistance of PCB (SB) section B: (a) group A under concentrated loads; (b) group A under distributed loads; (c) group B under concentrated loads; (d) group B under distributed loads

flange that produced the prestressing moment with a constant value along the beam length, resisting the applied moment. The prestressing bending moment diagram is closer to the distributed load bending moment diagram than the bending moment of concentrated loads. Therefore, the effect of prestressing on beams under distributed loads is more significant than for those under concentrated loads using a straight tendon above the bottom flange.
Figure 8 also shows the effect of changing steel flanges area ratio in the presence of prestressing force applied on composite beams. The initial prestressing force applied on the tendon was assumed to be $0 \cdot 40 F_{\mathrm{y}}$ and the concrete deck thickness-to-width ratio was $h_{\mathrm{c}} / B_{\mathrm{c}}=0 \cdot 10$. These values are considered standard for similar figures hereafter. Figures $8(\mathrm{a})$ and $8(\mathrm{~b})$ present the relation between ultimate moment ratio $\left(M_{\mathrm{u}} / M_{\mathrm{u} 0}\right)$ and steel flanges area ratio $\left(A_{\mathrm{fb}} / A_{\mathrm{ft}}\right)$ for beams of steel section group A 


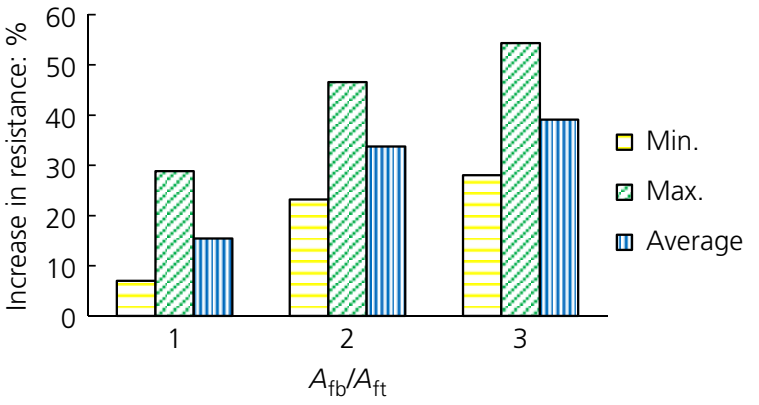

(a)

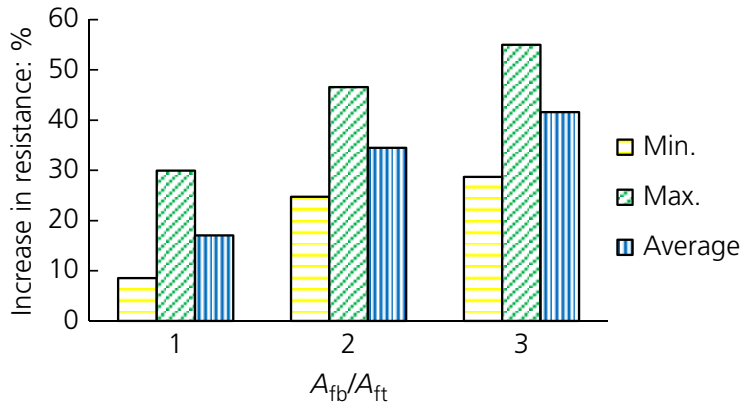

(b)

Figure 11. Effect of steel flange area ratio on the ultimate resistance of beams (DR): (a) under concentrated loads; (b) under distributed loads

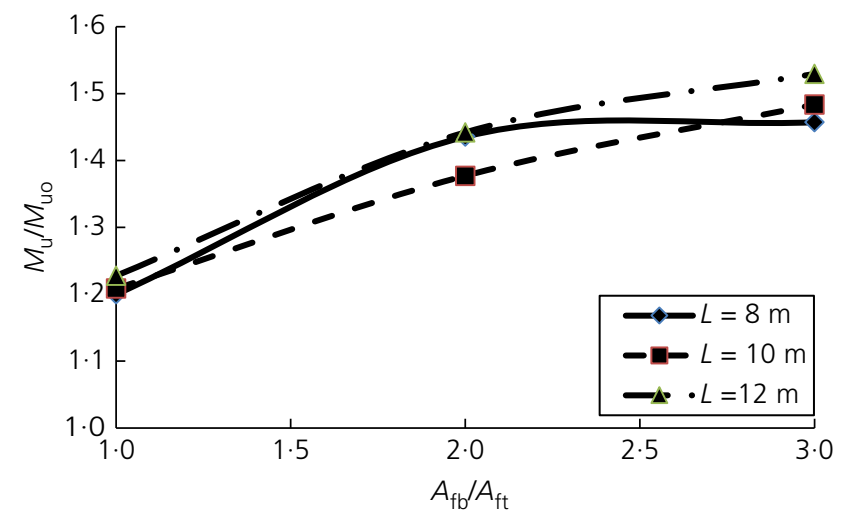

(a)

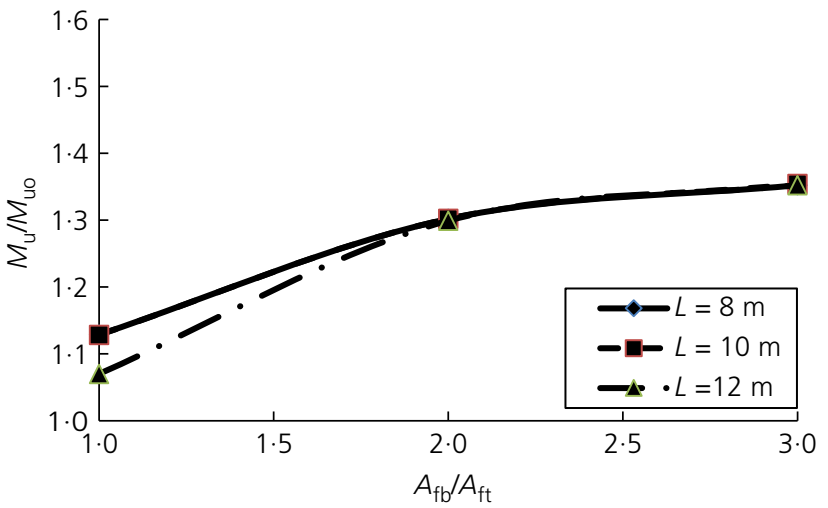

(c)

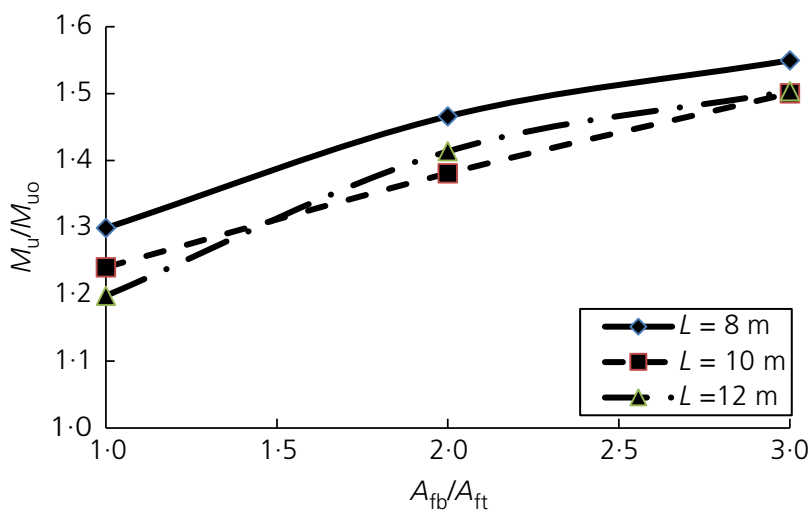

(b)

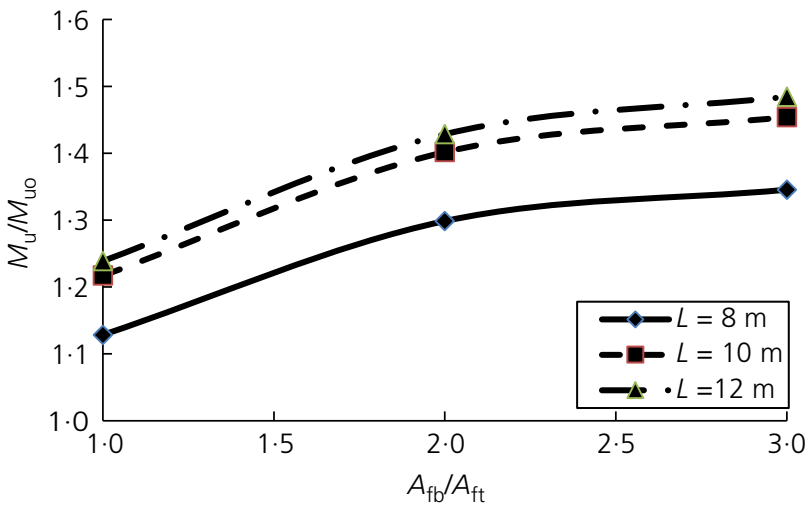

(d)

Figure 12. Effect of flange area ratio on the ultimate resistance of PCB (DR) section B: (a) group A under concentrated loads; (b) group A under distributed loads; (c) group B under concentrated loads; (d) group B under distributed loads

subjected to concentrated and distributed loads, respectively. The ultimate moment of beams of steel section group B is presented in Figures 8(c) and 8(d) for beams under concentrated and distributed loads, respectively. It can be noticed that there is a direct relation between ultimate moment and steel flanges area ratio. The ultimate moment ratio increased by increasing the steel flanges area ratio. The effect of prestressing is more significant on beams with $A_{\mathrm{fb}} / A_{\mathrm{ft}}$ ratio of less than two.
7.1.2 Straight tendon profile below tension flange (SB) Beams prestressed by the second tendon profile (SB) are investigated in this section. Figures 9(a) and 9(b) present the maximum, minimum and average values of percentage increase in resistance for beams subjected to concentrated and distributed loads, respectively. It can be observed that increasing the steel flanges area ratio led to enhancing the ultimate resistance. This was noticed for the studied beams under concentrated and 
distributed loads. The percentage increase in resistance of beams under distributed loads is more significant than that for beams under concentrated loads. To thoroughly investigate the behaviour, the results were divided into groups and they are compared individually hereafter. Results of beams having steel section group A are presented in Figures 10(a) and 10(b). Results of prestressed composite beams of steel section group B are presented in Figures 10(c) and 10(d). A direct relationship between the steel flanges area ratio and ultimate moment ratio was observed. The ultimate resistance increased by increasing steel flanges area ratio, especially for $A_{\mathrm{fb}} / A_{\mathrm{ft}}$ less than two.

\subsubsection{Draped tendon profile (DR)}

Beams prestressed by draped tendon profile are investigated in this section. The maximum, minimum and average values of the percentage increase in resistance are presented in Figure 11. It can be observed that the ultimate resistance of beams with draped tendon increased by increasing the steel flange area ratio. In addition, it was noticed that the effect of prestressing of composite beams under distributed loads is larger than for beams under concentrated loads with a minor difference (less than $2 \%$ ). To avoid the effect of other parameters affecting the resistance of beams, Figures 12(a) and 12(b) present the relation between ultimate moment ratio and steel flanges area ratio for beams of group A. Results for the prestressed composite beams of group B are presented in Figures 12(c) and 12(d). As shown in these figures, increasing the steel flanges area ratio led to a higher ultimate moment ratio.

It can be seen from Figures 7-12 that increasing the steel flange area ratio resulted in higher ultimate resistance. Increasing the $A_{\mathrm{fb}} / A_{\mathrm{ft}}$ ratio from 1 to 3 led to an average increase in the ultimate moments of beams under concentrated loads from 15.4 to $41.6 \%$, and an increase in the resistance of beams under distributed loads from $17 \cdot 1$ to $46 \cdot 1 \%$. This was in agreement with the work carried out by Ibrahim et al. (2012), where they found that the unsymmetrical I-section steel beam with wider bottom flange used in prestressed composite steelconcrete beam is more effective without change of the total cross-sectional area. They found also that the increase in the ultimate load of beams subjected to four-point loads (nearly distributed load) was greater than that in the beams subjected to a mid-span single load.

\subsection{Effect of beam span ( $L$ )}

The parametric study covers a range of spans from 8.00 to $16.00 \mathrm{~m}$. The effect of prestressing composite beams with

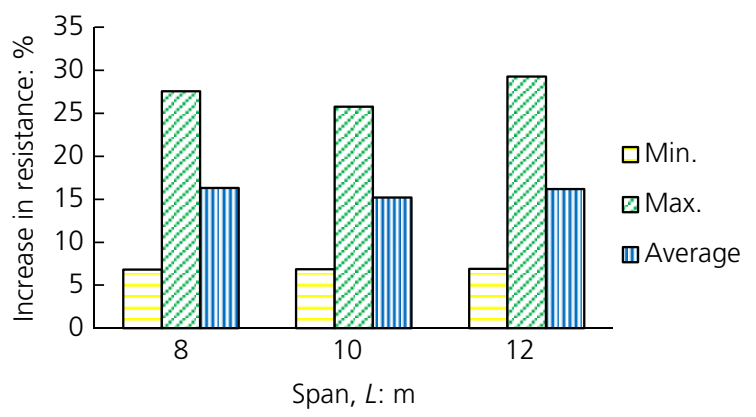

(a)

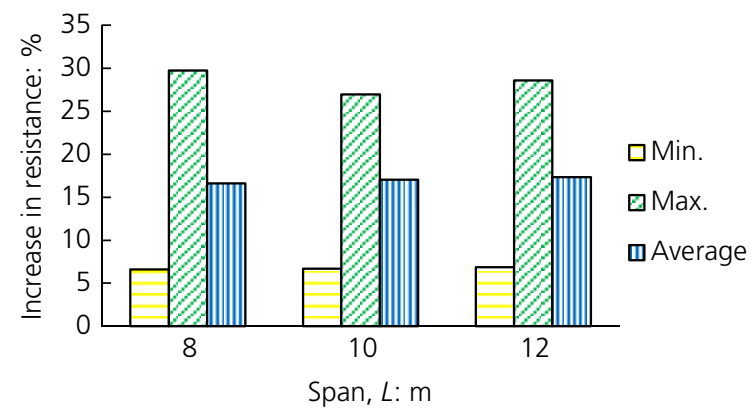

(b)

Figure 13. Effect of beam span on the ultimate resistance of beams (SA) sections A and B: (a) under concentrated loads; (b) under distributed loads

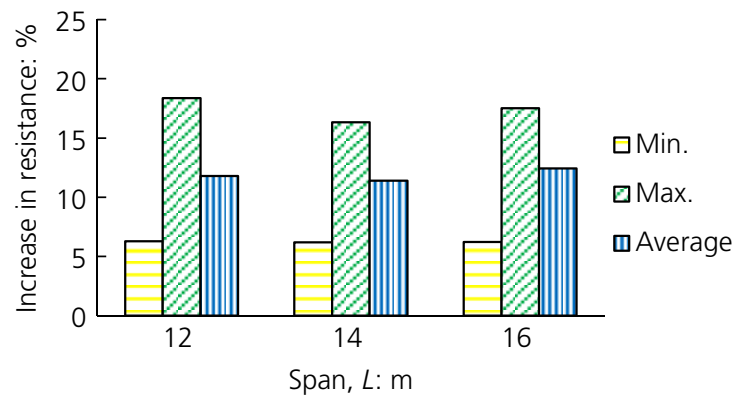

(a)

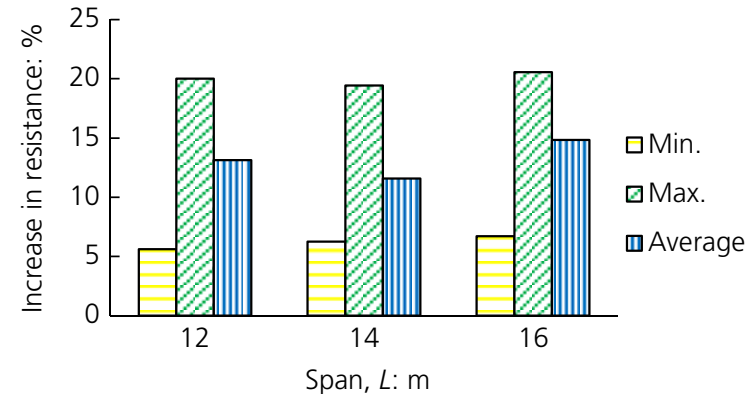

(b)

Figure 14. Effect of beam span on the ultimate resistance of beams (SA) sections C and D: (a) under concentrated loads; (b) under distributed loads 
different spans is studied. The studied beams are divided into groups according to the prestressing tendon profile. Each prestressed composite beam is compared with the corresponding non-prestressed composite beam, as will be discussed in the next subsections and as shown in Figures 13-20.

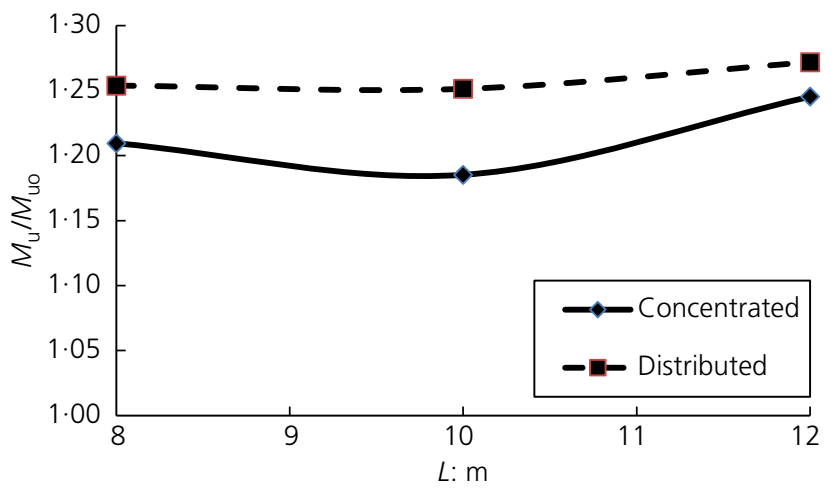

(a)
7.2.1 Straight tendon profile above tension flange (SA) Statistical data for prestressed composite beams subjected to concentrated and distributed loads are presented in Figures 13 and 14 for beams of steel section depth of 500 and $750 \mathrm{~mm}$, respectively. These figures presented the minimum, maximum

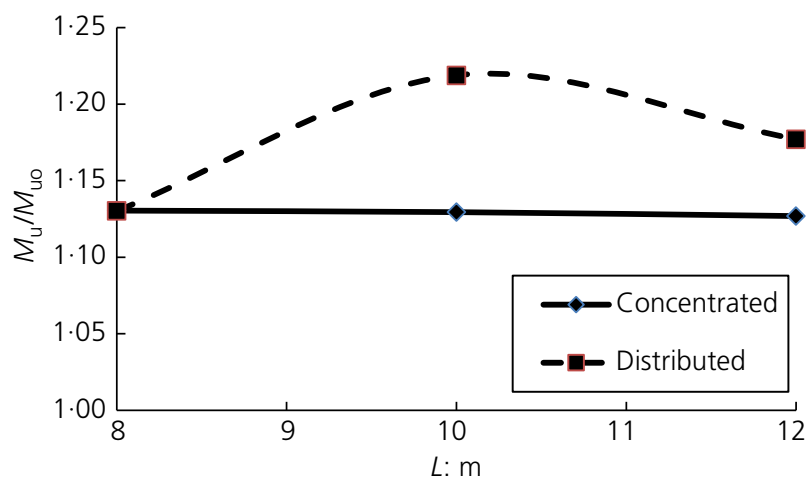

(b)

Figure 15. Effect of beam span on the ultimate resistance of $\mathrm{PCB}(\mathrm{SA})\left(h_{\mathrm{w}}=500 \mathrm{~m}\right)$ : (a) section $\mathrm{A} 1$; (b) section $\mathrm{B} 1$

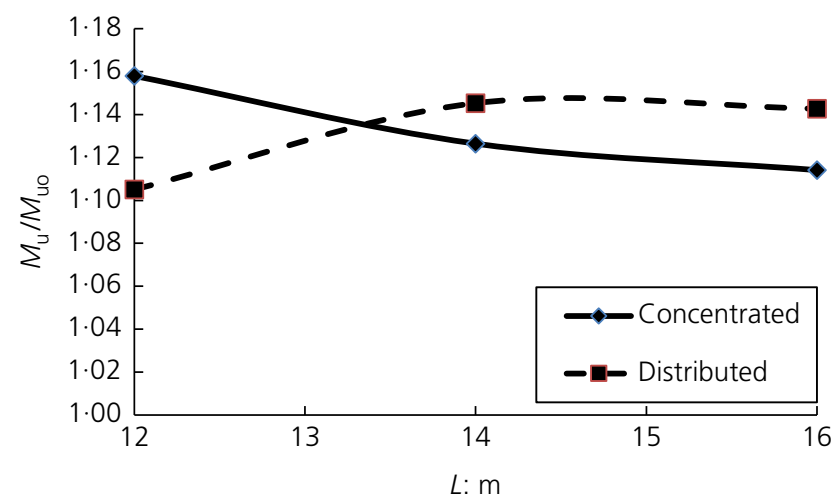

(a)

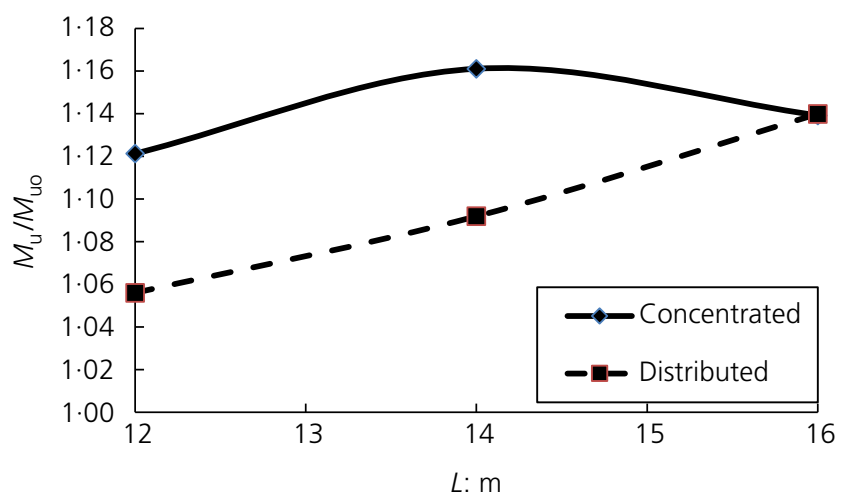

(b)

Figure 16. Effect of beam span on the ultimate resistance of PCB (SA) $\left(h_{w}=750 \mathrm{~m}\right)$ : (a) section C1; (b) section D1

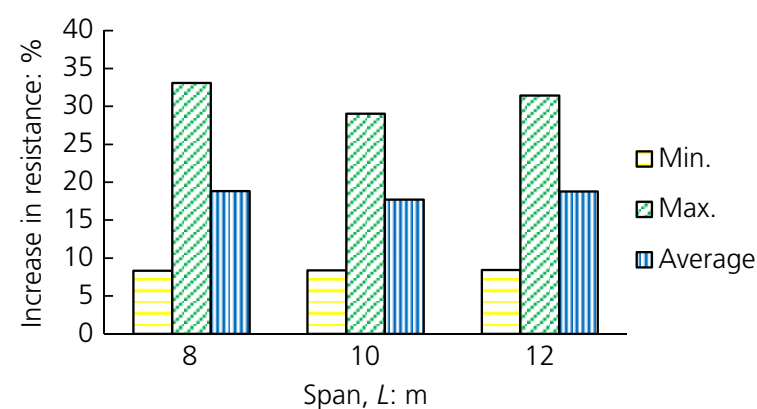

(a)

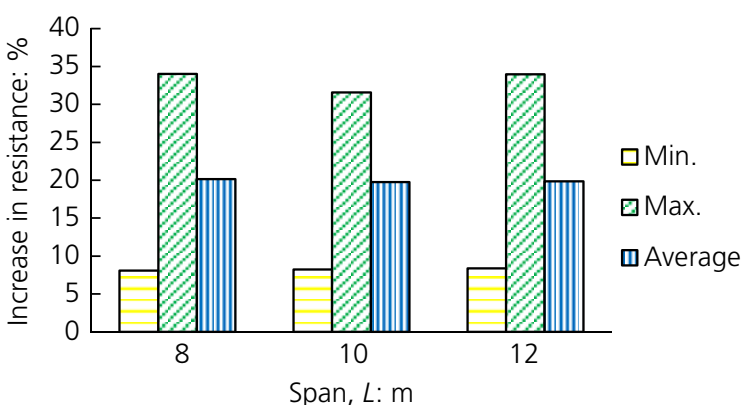

(b)

Figure 17. Effect of beam span on the ultimate resistance of beams (SB) sections A and B: (a) under concentrated loads; (b) under distributed loads 
and average percentage increase in the ultimate resistance of beams. It can be seen from the figures that the ultimate resistance tends to increase by increasing span with minor variation between different spans. Figure 15 shows the effect of changing beam span on the ultimate moment resistance of beams with steel sections A1 and B1. It can be seen from Figure 15 that increasing the beam span led to an enhancement of the ultimate resistance of beams generally. However, the ultimate

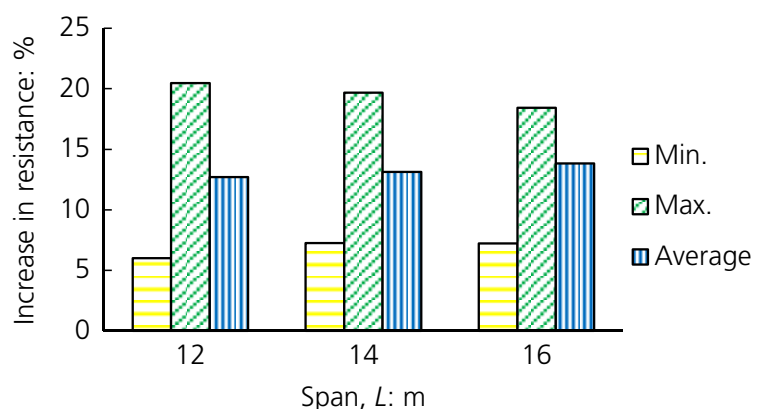

(a)

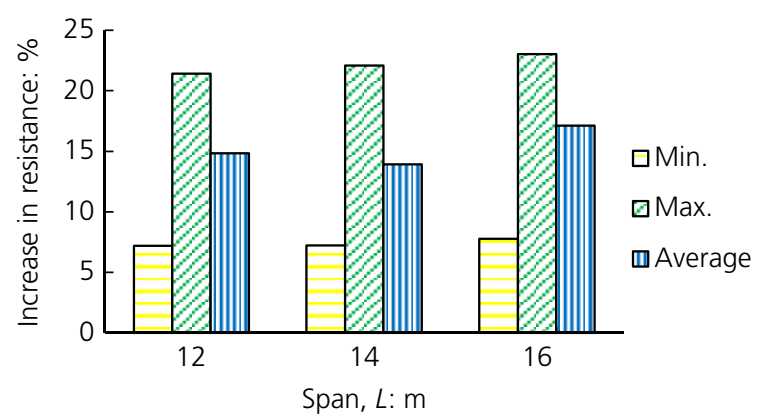

(b)

Figure 18. Effect of beam span on the ultimate resistance of beams (SB) sections C and D: (a) under concentrated loads; (b) under distributed loads

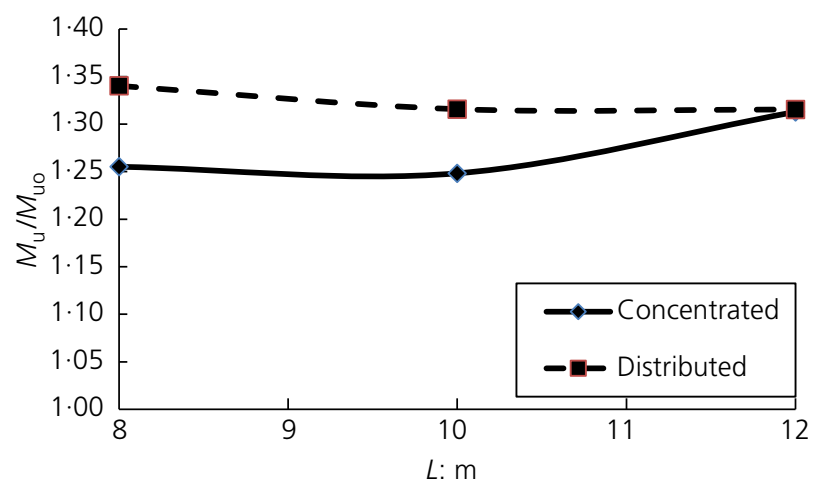

(a)

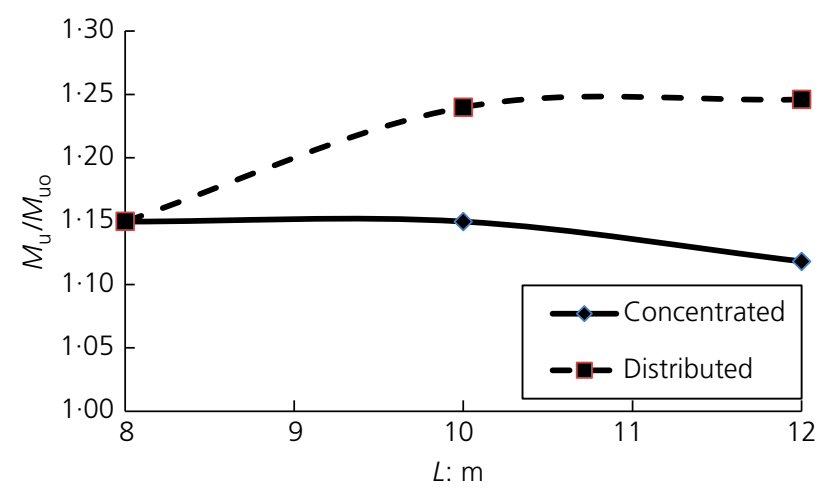

(b)

Figure 19. Effect of beam span on the ultimate resistance of $\mathrm{PCB}(\mathrm{SB})\left(h_{\mathrm{w}}=500 \mathrm{~m}\right)$ : (a) section $\mathrm{A} 1$; (b) section $\mathrm{B} 1$

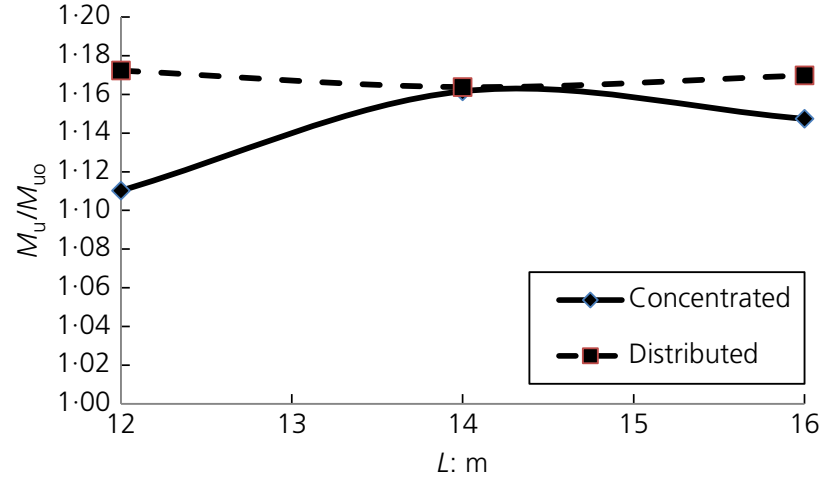

(a)

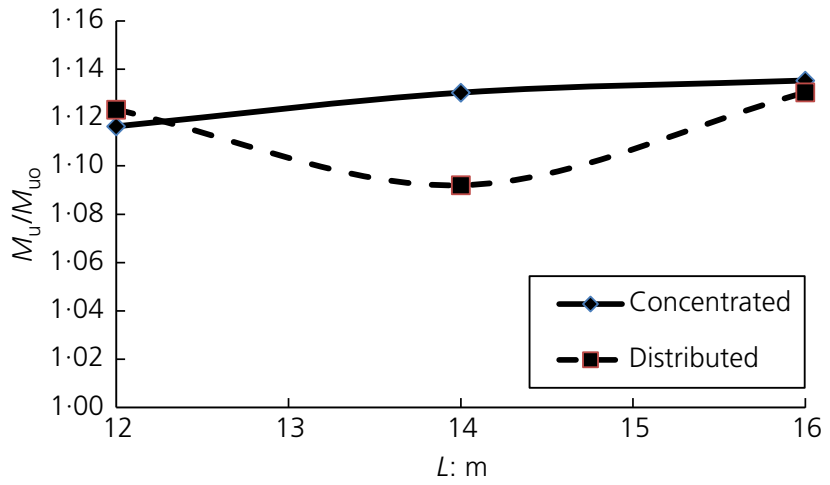

(b)

Figure 20. Effect of beam span on the ultimate resistance of PCB (SB) $\left(h_{w}=750 \mathrm{~m}\right)$ : (a) section C1; (b) section D1 
moment resistance of beams under distributed loads of section A1 was slightly affected by the changing beam span, as shown in Figure 15(a), and the beams of section B1 under concentrated loads showed the same slight effect on the ultimate moment resistance by increasing span. Figure 16(a) presents the ultimate resistance of beams having steel sections $\mathrm{C} 1$. The general trend of these beams is the reduction in ultimate resistance by increasing beam span. Figure 16(b) shows that the increase in beam span led to enhancement of the ultimate moment resistance for beams with steel section D1.

\subsubsection{Straight tendon profile below tension flange (SB)}

Results of the parametric study of composite beams prestressed by straight tendon below the bottom flange are discussed hereafter. Figures 17 and 18 show the results of beams under concentrated and distributed loads, for depths of 500 and $750 \mathrm{~mm}$, respectively. It can be seen from the figures that, generally, changing span has a minor effect on the percentage increase in the resistance. Figure 19(a) shows the effect of changing beam span on the ultimate resistance for beams with section A1. It can be seen from the figure that the ultimate

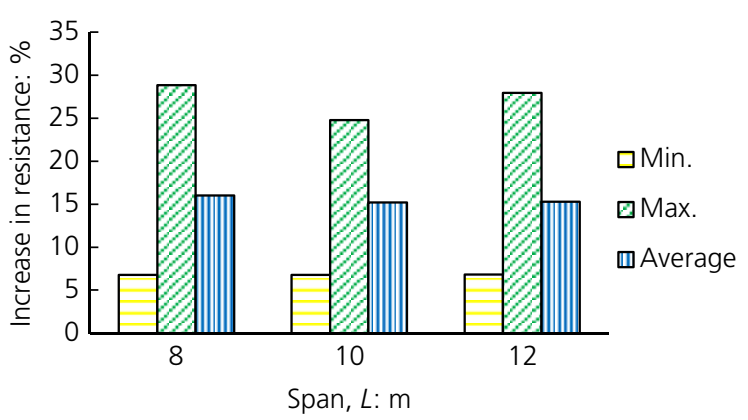

(a) resistance of beams under concentrated loads increases by increasing beam span, but in contradiction, it decreases for beams under distributed loads. It can be seen from Figure 19(b) that the ultimate resistance of beams of section B1 under concentrated loads decreases by increasing beam span, whereas it increases by increasing beam span for beams under distributed loads. For beams of sections C1 and D1, Figure 20 shows that the ultimate resistance varied with changing the beam span without any definite pattern.

\subsubsection{Draped tendon profile (DR)}

Figures 21 and 22 show the comparison between the ultimate resistance of beams under concentrated loads and distributed loads for steel sections with depth of 500 and $750 \mathrm{~mm}$, respectively. Generally, the percentage of increase in the ultimate resistance reduced by increasing span with minor variation in resistance for different $h_{\mathrm{c}} / B_{\mathrm{c}}$ ratios. Figures 23(a) and 23(b) show the effect of changing beam span on the ultimate resistance of beams of sections A1 and B1. No obvious trend could be observed for these beams. Figure 24(a) presents the ultimate resistance of beams having section $\mathrm{C} 1$. The effect of changing

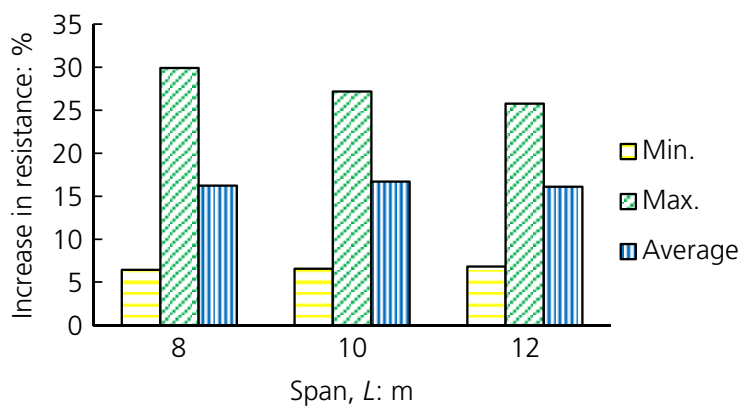

(b)

Figure 21. Effect of beam span on the ultimate resistance of beams (DR) sections A and B: (a) under concentrated loads; (b) under distributed loads

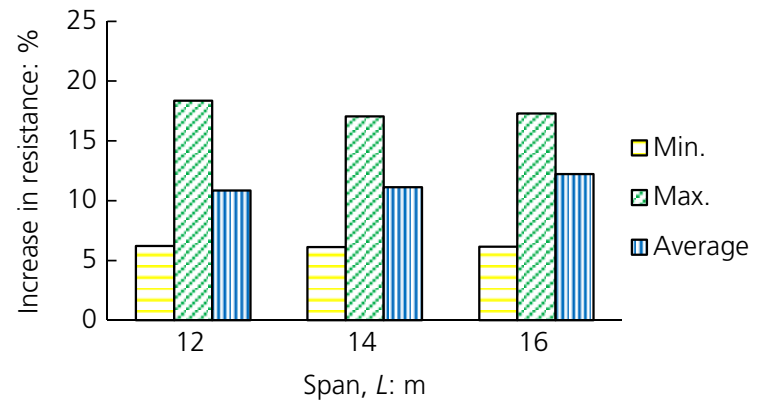

(a)

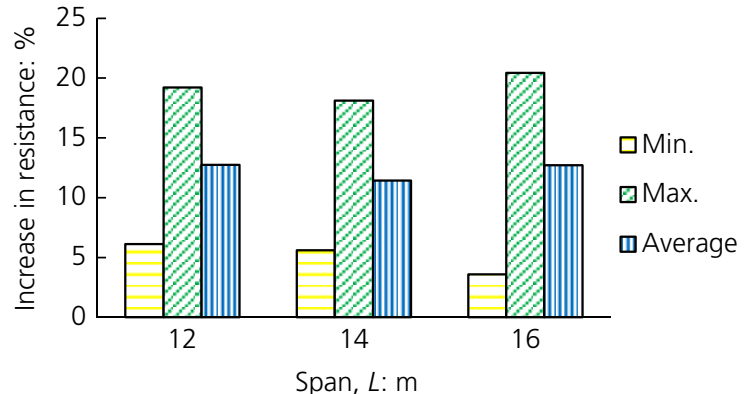

(b)

Figure 22. Effect of beam span on the ultimate resistance of beams (DR) sections C and D: (a) under concentrated loads; (b) under distributed loads 
beam span on the ultimate resistance can be ignored for those beams. For beams of section D1, Figure 24(b) shows that increasing the beam span led to an increase in the ultimate resistance of these beams. It can be concluded that the effect of beam span variation has a minor effect on increasing the ultimate resistance of prestressed composite beams compared to the corresponding non-prestressed composite beams. The beam resistance is governed by the cross-sectional capacity, not the overall beam capacity. This may be attributed to the high resistance of composite beams to lateral buckling, owing to the presence of a wide concrete deck in the compression zone. Therefore, the ultimate resistance is affected by changing the geometry of the crosssection rather than changing the beam span.

\subsection{Effect of concrete deck thickness-to-width ratio}

The effect of changing the concrete deck thickness-to-width ratio $\left(h_{\mathrm{c}} / B_{\mathrm{c}}\right)$ is discussed for three types of tendon profiles. A general view of the results is presented, based on statistical data. In addition, a thorough discussion of the behaviour of beams with sections $\mathrm{A} 1$ and $\mathrm{B} 1$ is presented in the next subsections and the results are shown in Figures 25-30.

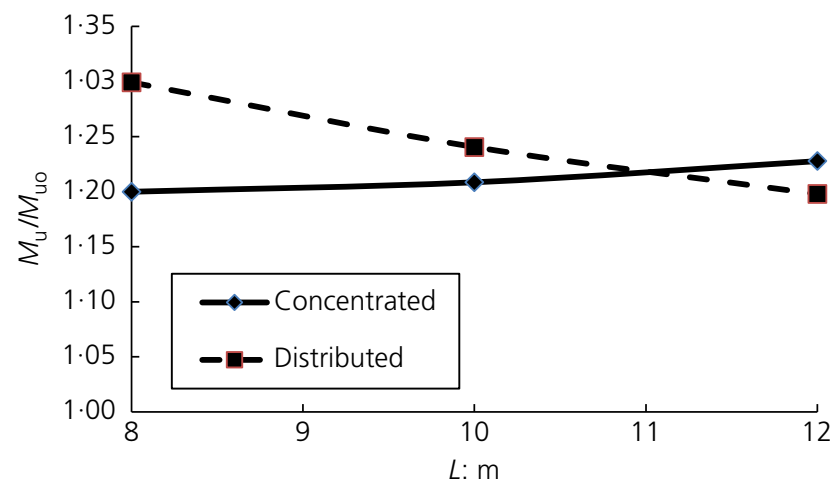

(a)
7.3.1 Straight tendon profile above tension flange (SA) The maximum, minimum and average percentages of increase in the ultimate resistance are shown in Figure 25. It can be seen from the figure that the percentage of increase in the ultimate resistance, due to prestressing, slightly increased by increasing the concrete deck thickness-to-width ratio. Figure 26 gives a better understanding of the effect of changing the concrete deck thickness-to-width ratio in the presence of prestressing applied on composite beams. The ultimate moment $\left(M_{\mathrm{u}}\right)$ is considered for beams having the aforementioned standard values. The ultimate moment of the non-prestressed composite beams $\left(M_{\mathrm{u} 0}\right)$ is considered for the corresponding beam with concrete deck thickness-to-width ratio, $h_{\mathrm{c}} / B_{\mathrm{c}}=0 \cdot 10$. Figures 26(a) and 26(b) show the results for section A1. It can be seen from the figures that the ultimate moment ratio increased by increasing the concrete deck thickness-to-width ratio for beams under concentrated and distributed loads. The ultimate moment ratios of beams of section B1 are presented in Figures 26(c) and 26(d). There is a direct relationship between ultimate moment and concrete deck thickness-to-width ratio.

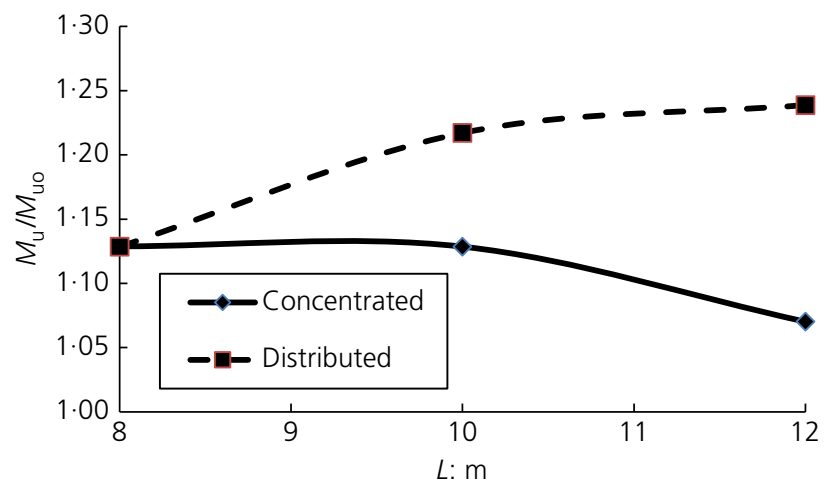

(b)

Figure 23. Effect of beam span on the ultimate resistance of $P C B(D R)$ sections $A 1$ and $B 1$ : (a) section $A 1$; (b) section $B 1$

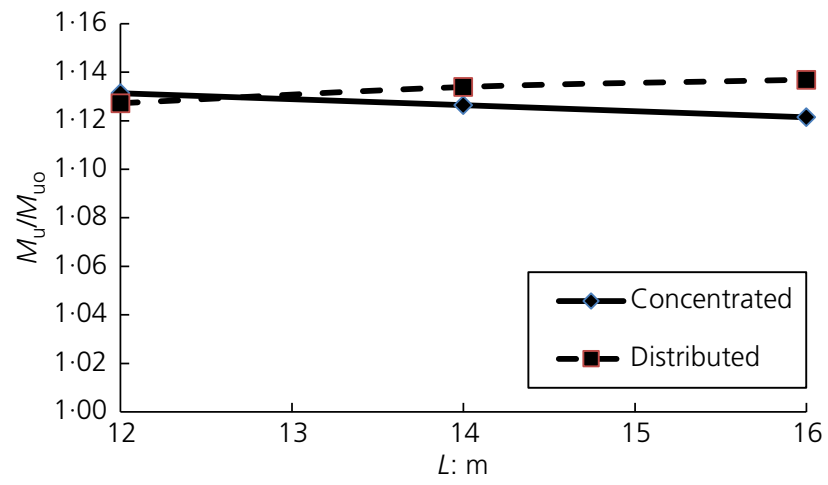

(a)

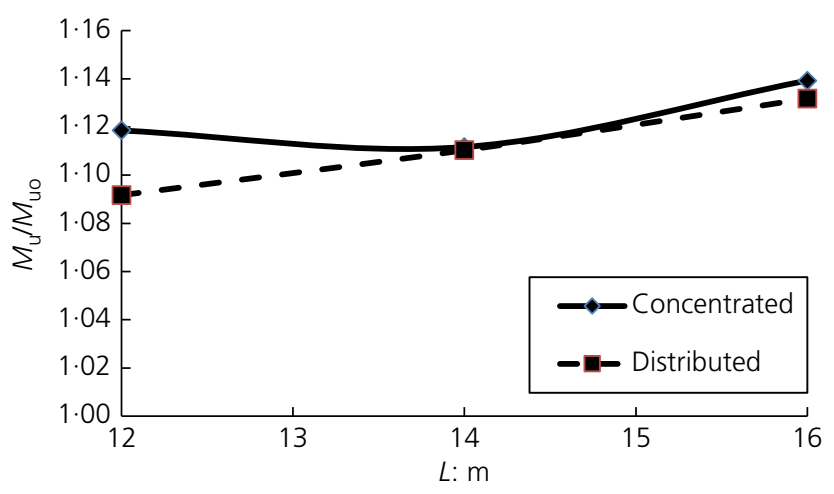

(b)

Figure 24. Effect of beam span on the ultimate resistance of PCB (DR) sections C1 and D1: (a) section C1; (b) section D1 


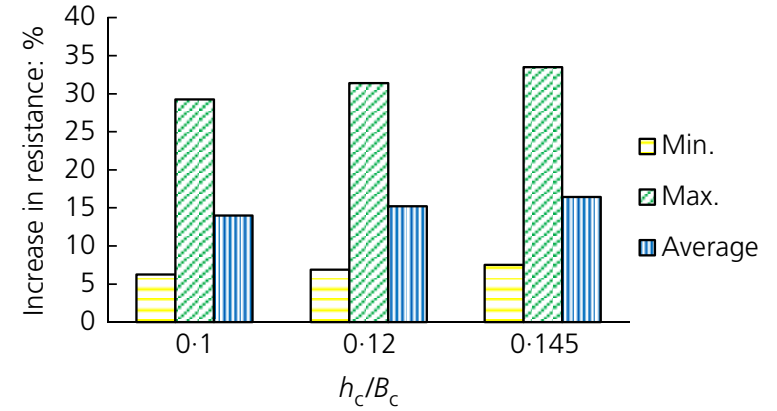

(a)

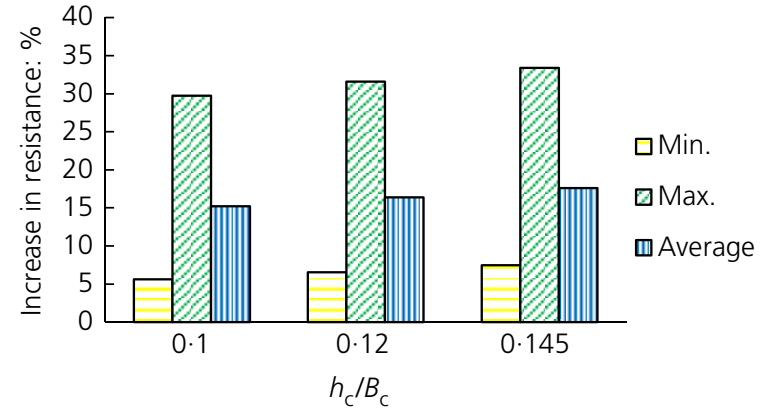

(b)

Figure 25. Effect of concrete deck thickness-to-width ratio on the ultimate resistance of beams: (a) under concentrated loads; (b) under distributed loads

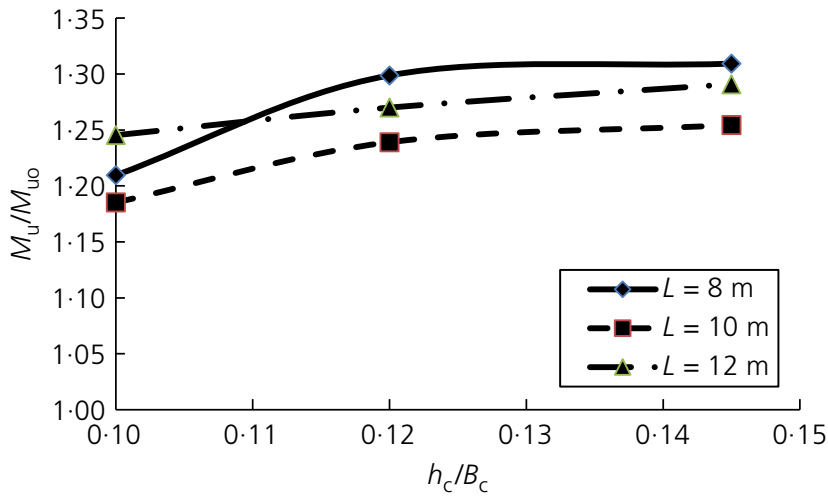

(a)

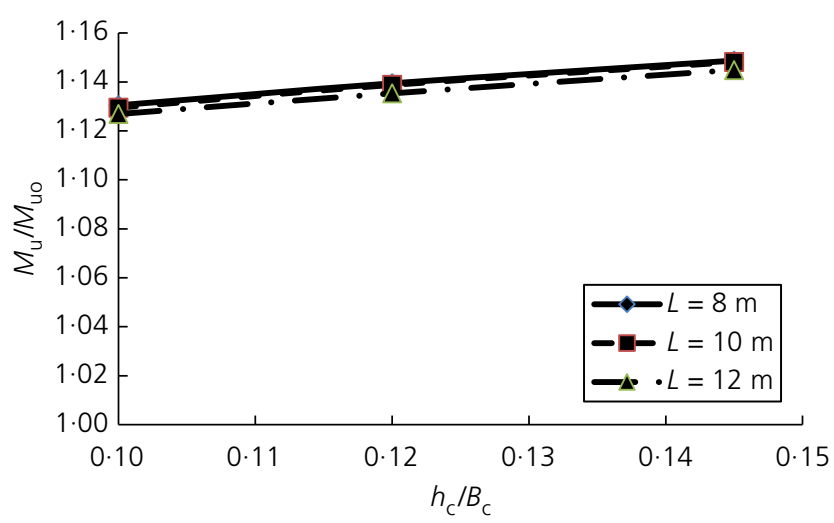

(c)

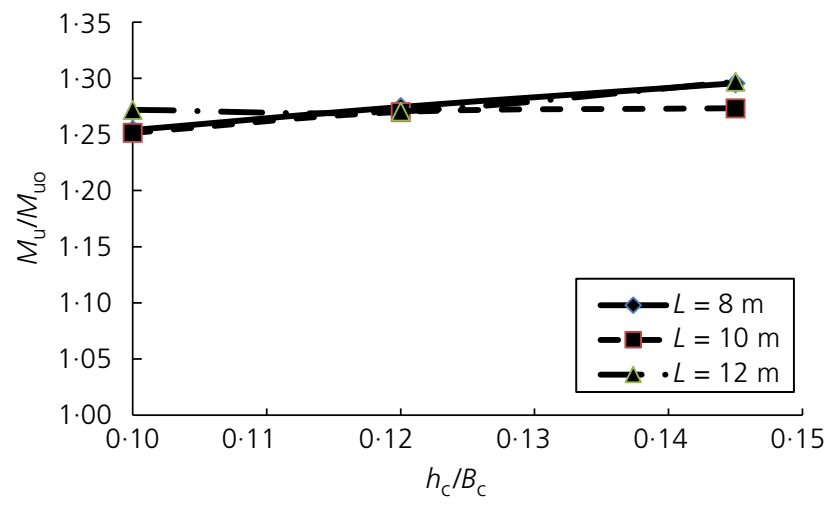

(b)

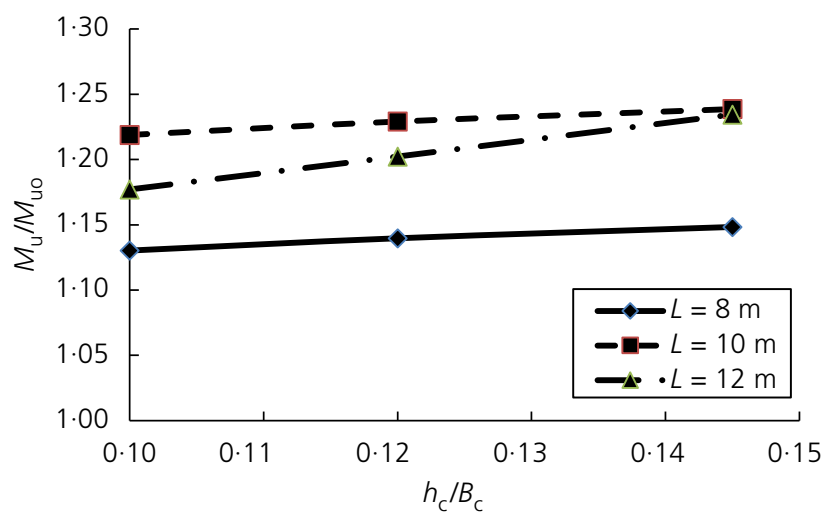

(d)

Figure 26. Effect of concrete deck thickness-to-width ratio on the ultimate resistance of PCB (SA): (a) group A under concentrated loads; (b) group A under distributed loads; (c) group B under concentrated loads; (d) group B under distributed loads

7.3.2 Straight tendon profile below tension flange (SB) Beams prestressed by straight tendon below the bottom flange are investigated in this section. The percentage of increase in resistance is shown in Figure 27. It can be seen from the figure that the rate of increase in ultimate resistance due to prestressing increased by increasing the concrete deck thickness-to-width ratio. To thoroughly investigate the behaviour, the results for beams having section A1 are presented in Figures 28(a) and 28(b). The ultimate resistance increases by increasing the concrete deck thickness-to-width ratio. In Figures 28(c) and 28(d), the results for prestressed composite beams of section B1 are presented. A clear direct relationship between concrete deck thickness-to-width ratio and ultimate moment ratio was also observed. 


\subsubsection{Draped tendon profile (DR)}

Figure 29 shows the maximum, minimum and average values of percentage increase in resistance. A notable increase was observed in the ultimate resistance due to prestressing by a draped tendon as the concrete deck thickness-to-width ratio increases. Figures 30(a) and 30(b) present the relation between ultimate moment ratio and concrete deck thickness-to-width ratio for beams of section A1. It can be seen from these figures that the ultimate moment ratio increased by increasing the concrete deck thickness-to-width ratio, generally, for beams under concentrated and distributed loads. Figures 30(c) and 30(d) show the direct relationship between ultimate resistance and concrete deck thickness-to-width ratio for prestressed composite beams of section B1.

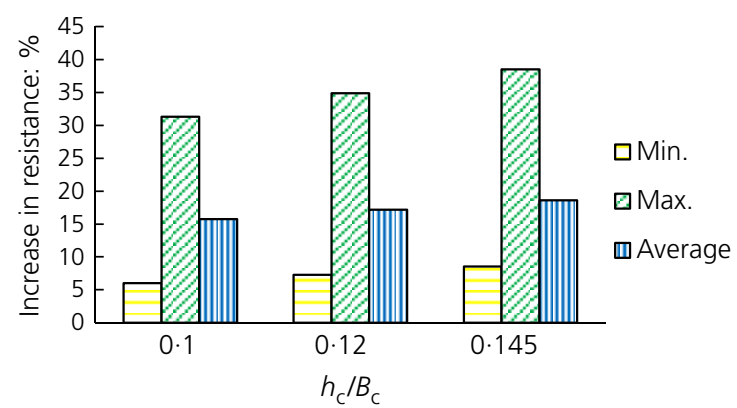

(a)

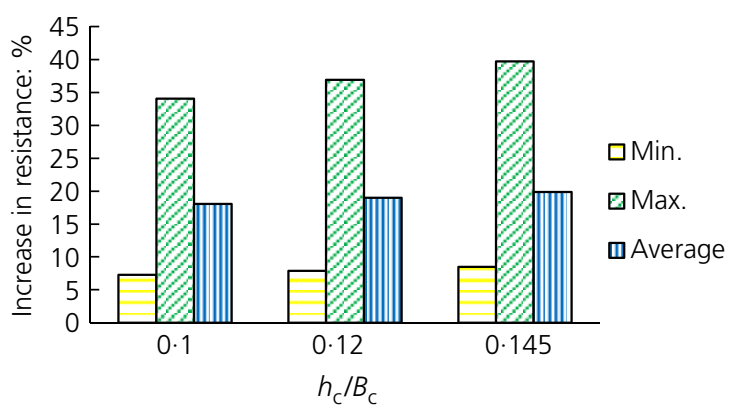

(b)

Figure 27. Effect of concrete deck thickness-to-width ratio on the ultimate resistance of beams (SB): (a) under concentrated loads; (b) under distributed loads

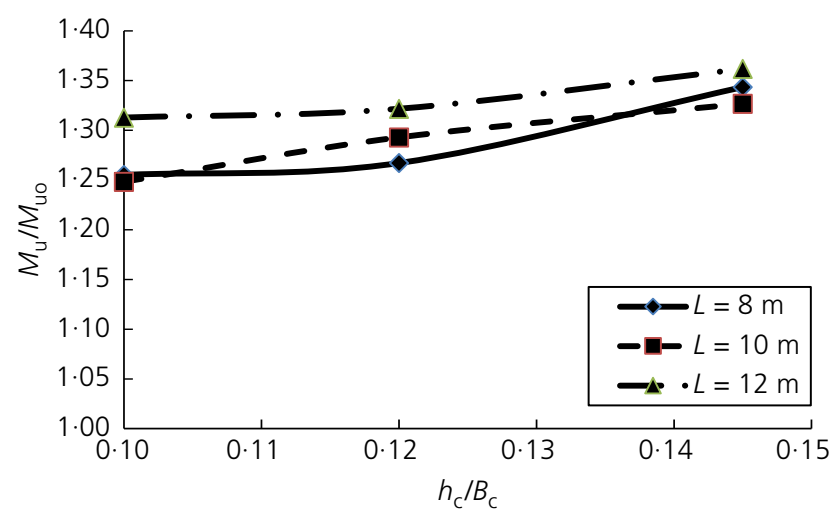

(a)

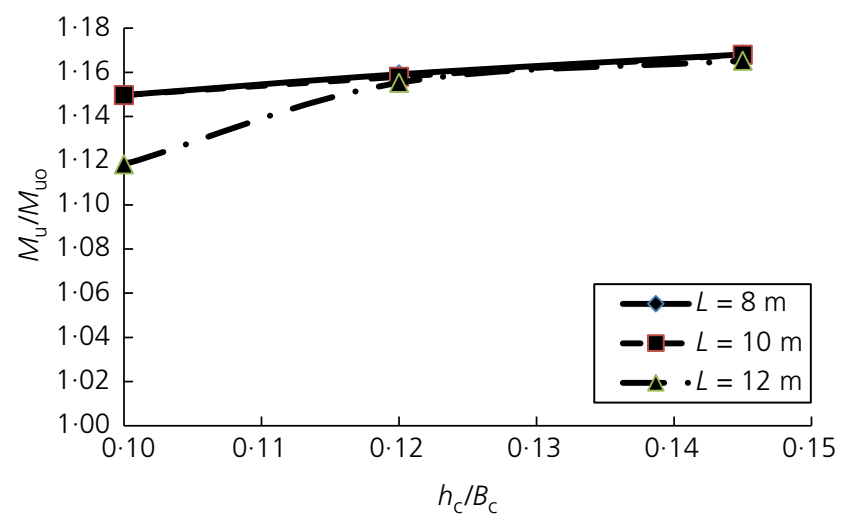

(c)

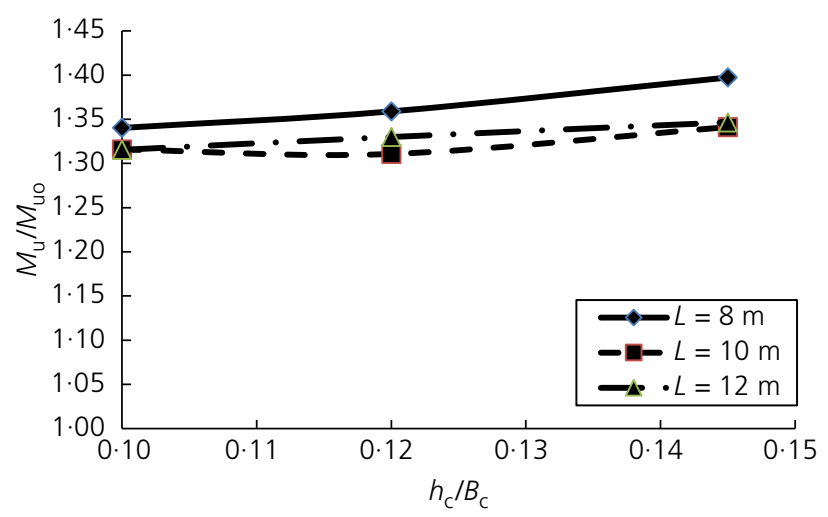

(b)

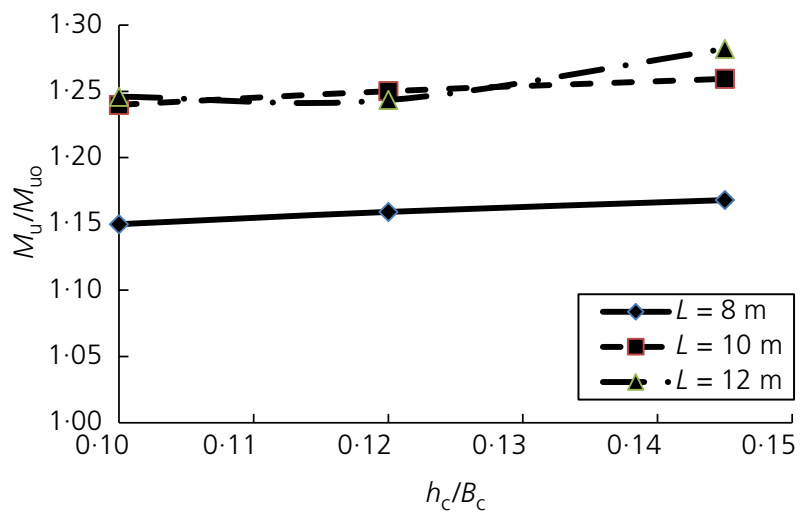

(d)

Figure 28. Effect of concrete deck thickness-to-width ratio on the ultimate resistance of PCB (SB): (a) group A under concentrated loads; (b) group A under distributed loads; (c) group B under concentrated loads; (d) group B under distributed loads 


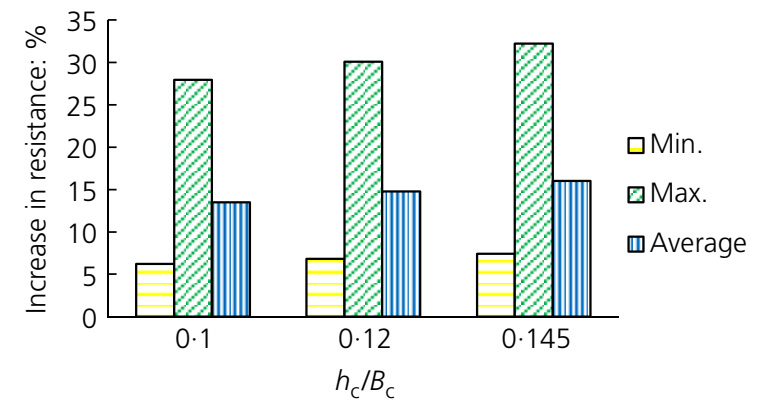

(a)

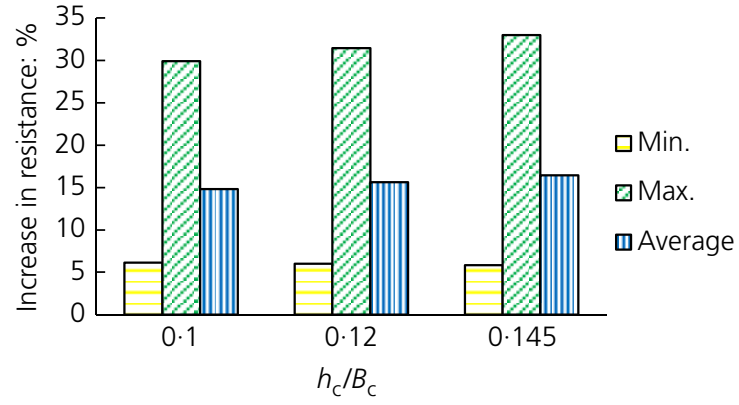

(b)

Figure 29. Effect of concrete deck thickness-to-width ratio on the ultimate resistance of beams (DR): (a) under concentrated loads; (b) under distributed loads

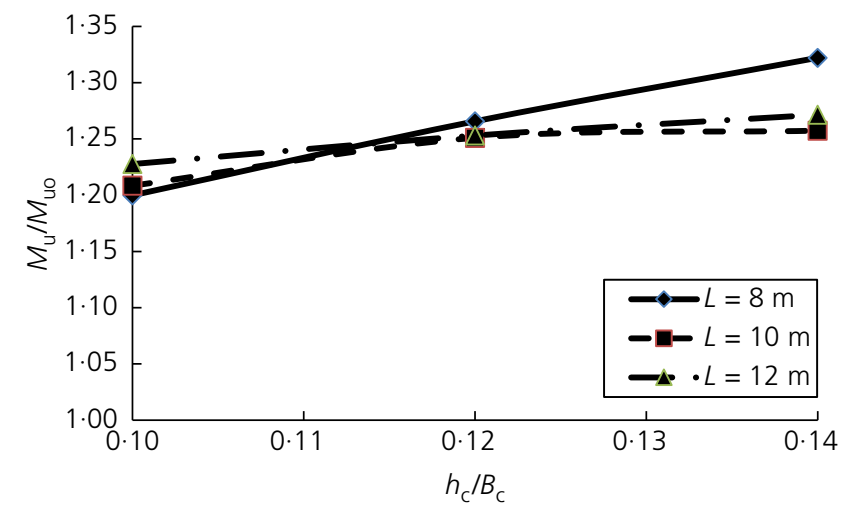

(a)

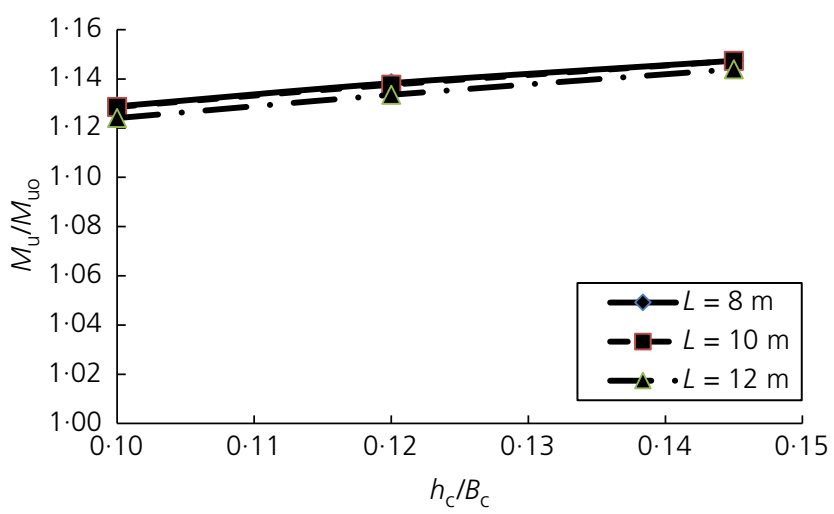

(c)

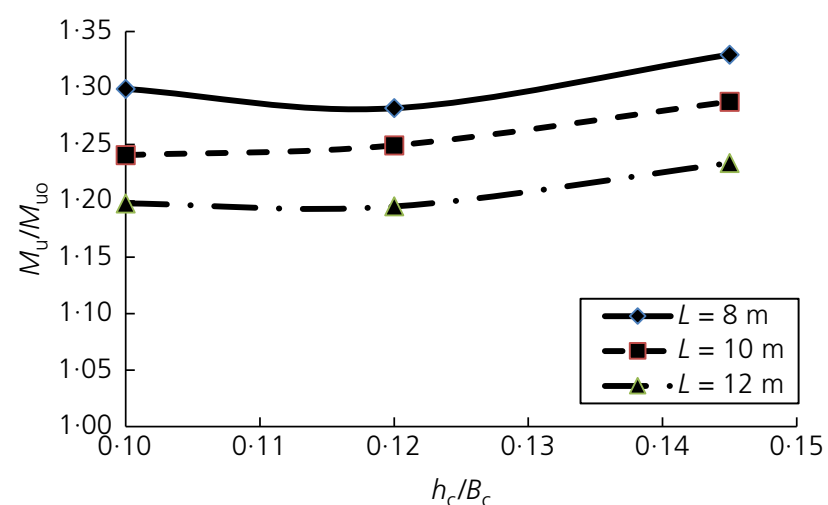

(b)

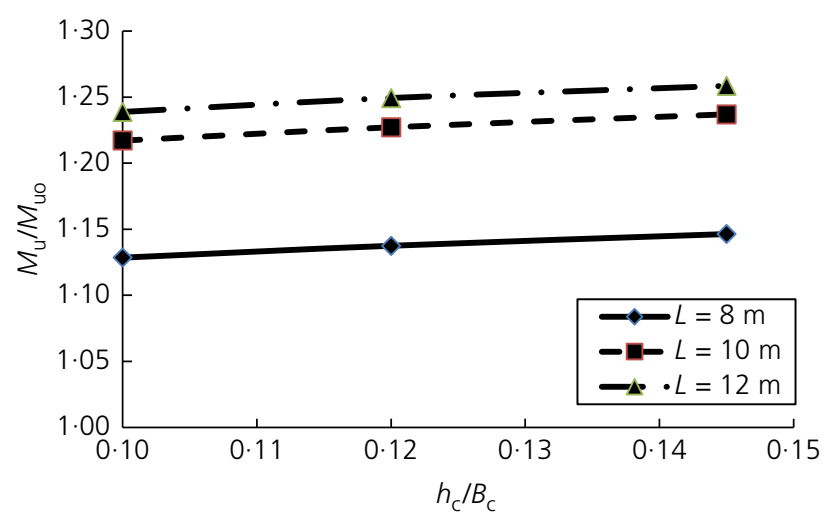

(d)

Figure 30. Effect of concrete deck thickness-to-width ratio on the ultimate resistance of PCB (DR): (a) group A under concentrated loads; (b) group A under distributed loads; (c) group B under concentrated loads; (d) group B under distributed loads

It can be observed from the above that there is a direct relationship between ultimate resistance and concrete deck thickness-to-width ratio, as the ultimate resistance increased by increasing $h_{\mathrm{c}} / B_{\mathrm{c}}$. This may be attributed to the increase in the total section depth and the more uniform distribution of compressive stresses on the concrete deck width, which increased by increasing $h_{\mathrm{c}} / B_{\mathrm{c}}$. This is in agreement with Ibrahim et al. (2012), who observed the same when they stated that the strengths of composite beams are increased by increasing the ratio of the depth to width of concrete slab, while keeping the total area of the concrete slab constant.

\section{Conclusions}

A parametric study has been performed for 2160 models using finite-element analysis. The adopted modelling procedure has been verified against two experimental tests on prestressed 
composite T-shaped beams from previous experimental work. The finite-element results for three geometric parameters have been presented and discussed. Some of the studied parameters are new, such as the effect of beam span. The other parameters had been investigated by previous researches with limited ranges. The investigated range of parameters in this study is wider than the range investigated by preceding research studies in the literature. The following conclusions can be drawn.

(a) It was found that there is a good agreement between the finite-element results of the model used in the present study and the published experimental results. This was indicated by the very close agreement between the load-deflection relationships and the ultimate loads predicted by the finite-element model and those of the experimental results. This ensures the reliability and accuracy of the adopted model in predicting and analysing the behaviour of externally prestressed composite beams.

(b) The ratio of the tension flange area (bottom) to the compression flange area (top) $\left(A_{\mathrm{fb}} / A_{\mathrm{ft}}\right)$ is the most effective geometrical parameter on the prestressed beam ultimate resistance. It is worth mentioning that the total area of the two flanges is constant in all cases; that is, the cross-sectional area is constant for each group of sections in this investigation.

(c) Increasing the $A_{\mathrm{fb}} / A_{\mathrm{ft}}$ ratio led to an increase of the ultimate resistance of the beam. It was found that increasing the $A_{\mathrm{fb}} / A_{\mathrm{ft}}$ ratio from 1 to 3 resulted in increasing the additional resistance of the beam due to prestressing from $15 \cdot 4$ to $46 \cdot 1 \%$. This is applicable for the three studied cable profiles and for beams under concentrated and distributed loads.

(d) Variation of the beam resistance with span has no particular trend. This is not usual in the case of non-composite steel beams. In the case of composite beams, the presence of the concrete slab prevented the lateral-torsional buckling and accordingly minimised the effect of the span.

(e) Increasing the slab thickness-to-width ratio resulted in enhancing the average increase in beam strength from $13 \cdot 5$ to $19 \cdot 9 \%$. This conclusion is applicable in all tendon profiles, all steel geometries and all load cases studied in this research. The actual stress distribution across the width of the concrete slab was implemented because the effect of the shear lag was considered by finite-element analysis inclusively.

( $f$ ) The current study shows that straight tendon profiles (SA and SB) are more appropriate for beams under distributed loads, whereas the draped tendon profile is more convenient for beams under concentrated loads. The straight tendon profile below the tension flange (SB) is slightly more efficient than the straight tendon profile above the tension flange (SA); the range of increase in ultimate resistance of beams with the SB profile was approximately from $3 \%$ up to $7 \%$.

\section{REFERENCES}

Aashto (American Association of State Highway and Transportation Officials) (2006) AASHTO LRFD Bridge Construction Specifications, 2nd edn. Aashto, Washington, DC, USA. Angomas FB (2009) Behavior of Prestressed Concrete Bridge Girders. MSc thesis, Utah State University, Logan, UT, USA (submitted). Ansys (2013) ANSYS 14.0, Coupled Structural/Thermal Analysis, (ANSYS Tutorials). University of Alberta, Edmonton, AB, Canada.

Ayyub B, Sohn Y and Saadatmanesh H (1990) Prestressed composite girders under positive moment. ASCE, Journal of Structural Engineering 116(11): 2931-2951.

Bukka RS, Shimpale PM and Lokhande RM (2016) Non linear analysis of composite beam slab junction with shear connectors using ANSYS. International Journal of Engineering and Science Invention 5(4): 22-29.

CEN (European Committee for Standardisation) (1993) DD ENV 1993-1-1: Eurocode 2: Design of concrete structures, part 1.1: general rules and rules for buildings. CEN, Brussels, Belgium.

Chandramohanmouli K and Kumar NH (2017) Finite element modeling of composite steel-concrete beams with external prestressing. International Journal of Engineering Development and Research 5(2): 1889-1907.

Chen S (2005) Experimental study of prestressed steel-concrete composite beams with external tendons for negative moments. Journal of Constructional Steel Research 61(12): 1613-1630.

Chen S and Gu P (2005) Load carrying capacity of composite beams prestressed with external tendons under positive moment. Journal of Constructional Steel Research 61(4): 515-530.

Chen S, Wang $X$ and Jia $Y$ (2009) A comparative study of continuous steel-concrete composite beams prestressed with external tendons: experimental investigation. Journal of Constructional Steel Research 65(7): 1480-1489.

Choi D, Kim Y and Yoo H (2008) External post-tensioning of composite bridges by a rating equation considering the increment of a tendon force due to live loads. Steel Structures $\mathbf{8 ( 2 )}$ : $109-118$.

Dabaon M, Sakr MA and Kharoub O (2005) Ultimate Behavior of Externally Prestressed Composite Beams with Partial Shear Connection. Department of Structural Engineering, Ain Shams University, Cairo, Egypt, Internal Report.

Dall'Asta A and Zona A (2005) Finite element model for externally prestressed composite beams with deformable connection. Journal of Structural Engineering, ASCE 131(5): 706-714.

Dall'Asta A, Ragni A and Zona A (2007) Simplified method for failure analysis of concrete beams prestressed with external tendons. Journal of Structural Engineering, ASCE 133(1) 121-131.

Desayi P and Krishnan S (1964) Equation for the stress-strain curve of concrete. Journal of the American Concrete Institute 61(3): 345-350.

El-Zohairy A and Salim H (2017) Parametric study for post-tensioned composite beams with external tendons. Advances in Structural Engineering 20(10): 1433-1450.

Ibrahim AM and Salman WD (2015) Parametric study of continuous composite steel-concrete beam with external prestressing. Engineering \& Technology Journal, Part A 33(3): 738-752.

Ibrahim AM, Mohaisen SK and Ahmed QW (2012) Finite element modeling of composite steel-concrete beams with external prestressing. International Journal of Civil and Structural Engineering 3(1): 101-116.

Ibrahim AM, Mohaisen SK and Ahmed QW (2015) Parametric study of composite steel-concrete beams with external prestressing. International Journal of Scientific and Engineering Research 6(4): 1261-1269. 
Kambal ME and Jia Y (2017) Analysis of behavior of steel box girders prestressed with external tendons. The Open Civil Engineering Journal 11. See https://www.benthamopen.com/EPUB/BSPTOCIEJ-2016-234 (accessed 18/06/2018).

Kim KS and Lee DH (2011) Flexural behavior of prestressed composite beams with corrugated web: part II. Experiment and Verification. Composites Part B Engineering 42(6): 1617-1629.

Liban RI and Tayşi N (2017) Nonlinear finite element analysis of composite cantilever beam with external prestressing. International Journal of Civil, Environmental, Structural, Construction, and Architectural Engineering 11(4): 511-517.

Lorenc W and Kubica E (2006) Behavior of composite beams prestressed with external tendons: experimental study. Journal of Constructional Steel Research 62(12): 1353-1366.

Lou T and Xiang Y (2010) Numerical analysis of second-order effects of externally prestressed concrete beams. Structural Engineering and Mechanics 35(5): 631-643.

Nie J, Cai C, Zhou T and Li Y (2007) Experimental and analytical study of prestressed steel-concrete composite beams considering slip effect. ASCE, Journal of Structural Engineering 133(4): 530-540.
Saadatmanesh H, Albrecht P and Ayyub B (1989) Experimental study of prestressed composite beams. ASCE, Journal of Structural Engineering 115(9): 2348-2363.

Safan M and Kohoutkova A (2001) Experiments with externally prestressed continuous composite girders. Acta Polytechnica 41(3): 65-73.

Shiming C and Yuanlin J (2010) Numerical investigation of inelastic buckling of steel-concrete composite beams prestressed with external tendons. Thin-Walled Structures 48(3): 233-242.

Tiejiong L, Sergio MRL and Adelino VL (2016) Numerical modeling of externally prestressed steel-concrete composite beams. Journal of Constructional Steel Research 121: 229-236.

Zona A, Ragni L and Dall'Asta A (2009) Simplified method for the analysis of externally prestressed steel-concrete composite beams. Journal of Constructional Steel Research 65(2): 308-313.

Zong Z, Zheng Z, Fang Z and Che H (2002) Experimental study of external prestressed steel-concrete composite continuous beams. China Journal of Highway and Transport 15(2): 44-49.

\section{How can you contribute?}

To discuss this paper, please email up to 500 words to the editor at journals@ice.org.uk. Your contribution will be forwarded to the author(s) for a reply and, if considered appropriate by the editorial board, it will be published as discussion in a future issue of the journal.

Proceedings journals rely entirely on contributions from the civil engineering profession (and allied disciplines). Information about how to submit your paper online is available at www.icevirtuallibrary.com/page/authors, where you will also find detailed author guidelines. 